\title{
An oviraptorosaur adult-egg association from the Cretaceous of Jiangxi Province, China
}

\section{Authors: Xingsheng Jin, David J. Varricchio, Ashley W. Poust, \& Tao He}

This is an Accepted Manuscript of an article published by Taylor \& Francis in Journal of Vertebrate Paleontology on 2019-11-01, available online: https:// www.tandfonline.com/10.1080/02724634.2019.1739060.

Jin, Xingsheng, David J. Varricchio, Ashley W. Poust, and Tao He. "An Oviraptorosaur Adult-Egg Association from the Cretaceous of Jiangxi Province, China." Journal of Vertebrate Paleontology 39, no. 6 (November 2, 2019): e1739060. doi:10.1080/02724634.2019.1739060. 


\title{
An oviraptorosaur adult-egg association from the Cretaceous of Jiangxi Province, China
}

\author{
Xingsheng Jin , David J. Varricchio , Ashley W. Poust \& Tao He
}

To cite this article: Xingsheng Jin , David J. Varricchio, Ashley W. Poust \& Tao He (2019) An oviraptorosaur adult-egg association from the Cretaceous of Jiangxi Province, China, Journal of Vertebrate Paleontology, 39:6, e1739060, DOI: 10.1080/02724634.2019.1739060

To link to this article: https://doi.org/10.1080/02724634.2019.1739060 


\begin{abstract}
With abundant well-preserved clutches and several adult-clutch associations, oviraptorids provide some of the most detailed information on reproduction for dinosaurs. Here, we describe an oviraptorosaur closely associated with two eggs from the Upper Cretaceous Nanxiong Formation of Jiangxi Province, China, and discuss its implications for various reproductive hypotheses. The specimen consists of a partial skeleton (gastralia, pelvis, portions of both hind limbs, and tail), with one egg within the pelvic canal and the other just posterior to it, ventral to the anterior caudal vertebrae. Several geopetal features indicate that the individual came to rest on its left side, with the eggs likely extruded during buildup of abdominal gases during decomposition. Similarity of pubis, caudal vertebrae, and pes dimensions to recently described material from the formation, e.g., Tongtianlong and Jiangxisaurus, suggests oviraptorid affinities. The specimen provides additional association of elongatoolithid eggs and the oogenus Macroolithus with oviraptorosaurs and further evidence for monoautochronic ovulation, i.e., iterative laying of two eggs at daily or greater intervals. With each egg $36-48 \%$ the size predicted for a modern bird of the same adult mass, total egg production would be slightly lower to similar between this non-avian maniraptoran and Neornithes. Histological tissues and open neurocentral sutures indicate that this reproductively active individual was several years old but still growing at the time of death, a pattern observed in other non-avian maniraptorans. The complete absence of medullary bone in this egg-bearing individual may challenge the identification of this tissue in other dinosaurs more distantly related to birds.
\end{abstract}

\title{
INTRODUCTION
}

The unusual occurrences of embryonic remains or eggs within adult skeletons provide important information about the repro-ductive mode (e.g., oviparity, viviparity) for extinct taxa (e.g., Caldwell and Lee, 2001; Zelenitsky et al., 2008; O'Keefe and Chiappe, 2011; Liu et al., 2017). They also can potentially furnish information on clutch size, neonate size relative to adult, reproductive output, sexual maturity, dimorphism, and female-specific histological tissues (e.g., Knell et al., 2011; Lü et al., 2011; Cadena et al., 2018; Bailleul et al., 2019). A number of marine reptiles occur in association with embryonic remains within or adjacent to the adult skeleton. For example, ichthyosaurs described over a hundred years ago contain embryonic remains, demonstrating viviparity in this clade of fully marine rep-tiles (Pearce, 1846; Woodward, 1906; Liepmann, 1926). Speci-mens show embryos within the rib cage, partially extruded through the pelvic canal and outside the adult body cavity. Early interpretations suggested that death occurred during parturition

(Pearce, 1846), an interpretation also proposed by Motani et al. (2014) for a specimen of an early ichthyopterygian Chaohusaurus and suggested as a possibility for the mosasaur Carsosaurus (Caldwell and Lee, 2001). Caldwell and Lee (2001) based this conclusion on one perinate occurring outside the mother and two others posteriorly located within the abdomen. However, Liepmann (1926) and more recently Böttcher (1990) and McGowan (1991) suggested that the extrusion of embryos could have occurred postmortem due to either the internal buildup of gasses associated with decay within the adult or com-paction by overlying sediments.

Viviparity has been inferred for a variety of other marine rep-tiles based on similar specimens. A skeleton of the aquatic mosa-sauroid Carsosaurus preserves the remains of four embryos positioned with their skulls facing anteriorly (Caldwell and Lee, 2001). Their large size and fully formed bones indicate that they were born alive and tail first, as in modern cetaceans (Caldwell and Lee, 2001). The large, singular embryo associated with the plesiosaur Polycotylus is evidence of viviparity and a K-selected strategy similar to that of modern cetaceans (O'Keefe and Chiappe, 2011). Further, a specimen of the Triassic marine reptile Dinocephalosaurus with an enclosed embryo represents the first evidence of live birth in an archosauromorph (Liu et al., 2017). The occurrence of well-developed young associated with adults in other aquatic clades such as mesosaurs (Piñeiro 
et al., 2012), choristoderes (Ji et al., 2010), and basal sauroptery-gians (Cheng et al., 2004) may support the frequent independent evolution of viviparity in aquatic forms. But see Motani et al.(2014) for a contrary view.

In contrast to these aquatic forms, preservation of terrestrial vertebrates with embryos or eggs within adults is much more uncommon. Two specimens of the turtle Adocus preserve eggs within the carapace, providing a definitive link between this taxon and specific egg forms or ootaxa (Zelenitsky et al., 2008; Knell et al., 2011). The occurrence of two eggs, one within and the other just posterior to the pelvis, in the pterosaur Kunpengop-terus permits the recognition of both cranial and pelvic dimorph-ism within the taxon and monoautochronic ovulation (Lü et al., 2011; Wang et al., 2015). Monoautochronic ovulation describes the condition in which each ovary ovulates a single egg simul-taneously, followed by a period of inactivity; this produces clutches consisting of an egg pair in a variety of extant lizards (Smith et al., 1973).

Despite occasional suggestions of viviparity in dinosaurs (Bakker, 1986; Mikhailov, 1997), no embryonic remains have ever been found associated with an adult that would support this speculation. However, three non-avian dinosaur specimens have been described with internal eggs. A scattering of some 13 small (6-10 mm diameter) spherical objects occur within and outside of the type specimen of Compsognathus from the Jurassic of Germany. Although lacking eggshell, Griffiths (1993) inter-preted these as eggs based on the presence of phosphorus and sulfur and their ventral occurrence along the skeleton. However, they may represent a product of decay and gas for-mation (Reisdorf and Wuttke, 2012) or mature ovarian follicles (O'Connor et al., 2013). Chen et al. (1998) describe a specimen of the closely related Sinosauropteryx as having two larger $(37 \times 26 \mathrm{~mm})$ eggs preserved internally, potentially casting further doubt on the identification of the Compsognathus eggs. Neverthe-less, the largely twodimensional preservation in Sinosauropteryx and the absence of eggshell may challenge the identification of these features as eggs as well.

A pair of well-preserved eggs within the lower rib cage of a dinosaur from the Upper Cretaceous Nanxiong Formation of Jiangxi Province, China, permitted the association of the ootaxon Macroolithus yaotunensis with oviraptorosaurs (Sato et al., 2005). As implied by Chen et al. (1998) for Sinosauropteryx, Sato et al. (2005) interpret the presence of two relatively large eggs as indicative of monoautochronic ovulation, as first hypoth-esized for oviraptorosaurs and troodontids based on within-clutch egg pairing (Varricchio et al., 1997). Based on their orientation within the pelvic region, Sato et al. (2005) consider the oviraptor-osaur eggs as laid pointed end first.

Recently, Zheng et al. (2013) described three basal birds from the Lower Cretaceous of China with aggregations of mature or nearly mature ovarian follicles. Each individual bird retains a single mass, suggesting the presence of only one functional ovary. Bailleul et al. (2019) described a Cretaceous enantior-nithine with an internal mass of eggshell interpreted as a crushed pathological egg. These specimens indicate that basal birds reached sexual maturity before skeletal maturity (Zheng et al., 2013; Bailleul et al., 2019).

Here, we describe a new specimen from the Cretaceous of Jiangxi Province, China, consisting of a partial oviraptorosaur skeleton closely associated with two elongatoolithid eggs. This specimen provides relevant information about the taphonomy of adults with associated eggs or embryos, monoautochronic ovu-lation and the rate of reproductive output in theropod dinosaurs, and taxon-ootaxon associations. Additionally, the specimen affords the opportunity to compare sexual versus somatic matur-ity and to examine a reproductively active (i.e., adult) dinosaur for the presence of medullary bone. Establishing osteological fea-tures such as bone texture or skeletal fusion that can be used

independently from histology to gauge somatic and/or sexual maturity remains an important research goal in better understanding taxonomy (Irmis, 2007; Bailleul et al., 2016; Hone et al., 2016).

Further, many modern birds produce medullary bone in antici-pation of egg laying. Females deposit this complex tissue within the cavities or medullary spaces associated with red bone marrow within their long bones as a mineral reserve utilized during egg formation (Werning, 2018; Canoville et al., 2019). Recently, this tissue has been reported from the dinosaurs Tyran-nosaurus rex, Allosaurus, Tenontosaurus, and Dysalotosaurus (Schweitzer et al., 2005; Lee and Werning, 2008; Hübner, 2012), enantiornithine birds (O'Connor et al., 2018; Bailleul et al., 2019), and possibly two pterosaurs (Chinsamy et al., 2009; Prond-vai and Stein, 2014). Schweitzer et al. (2016) also recently provide biochemical support for their earlier identification of medullary bone in the same T.rexindividual. However, the purported medul-lary tissue in these archosaur examples remains problematic (Prondvai, 2017; O'Connor et al., 2018), because medullary-bone-like endosteal tissues can develop pathologically (Chinsamy and Tumarkin-Deratzian, 2009). We address maturity and medul-lary bone in this new egg-associated oviraptorosaur specimen through both gross examination and histological sampling.

Institutional Abbreviations-ES, Department of Earth Sciences, Montana State University, Bozeman, Montana, U.S.A.; IGM, Mongolian Institute for Geology, Ulaanbaatar, Mongolia; IVPP, Institute of Vertebrate Paleontology and Paleoanthropology; MPC, Paleontological Center of the Mongolian Academy of Sciences, Ulaanbaatar, Mongolia; NMNS, National Museum of Natural Science, Taipei, Taiwan; ZMNH, Zhejiang Museum of Natural History, Hangzhou, Zhejiang, China.

\section{MATERIALS AND METHODS}

\section{Geological Setting}

The Zhejiang Museum of Natural History collected ZMNH M8829 in 2011 after its discovery during blasting by a construction crew in the western industrial area of Longling Town, Nankang City, Jiangxi Province, China. This specimen comes from the Upper Cretaceous Nanxiong Formation of the Ganzhou Basin near the city of Nankang, in the southern part of the Jiangxi Province. This same formation has produced a wealth of oviraptorid material, including Shixinggia (Lü and Zhang, 2005), Banji (Xu and Han, 2010), Ganzhosaurus (Wang et al., 2013), Nankangia (Lü et al., 2013), Jiangxisaurus (Wei et al., 2013), Huanansaurus (Lü et al., 2015), and Tongtianlong (Lü et al., 2016) and Corythor-aptor (Lü et al., 2017), eggs with embryos (Wang et al., 2016), and a specimen with two internal eggs described by Sato et al. (2005).

The Cretaceous series of Jiangxi Province consists of widely distributed, red continental clastic material (Bureau of Geology and Mineral Resources of Zhejiang Province, 1989). The varie-gated sedimentary rocks of the stratigraphically lower Huoba-shan Group range from 1,500 to $2,700 \mathrm{~m}$ in thickness and contain lamellibranch bivalves and conchostracans. The overlying Ganzhou and uppermost Nanxiong formations are mainly brick-red clastic rocks, 2,400 to $8,900 \mathrm{~m}$ thick, that contain vertebrate fossils (Bureau of Geology and Mineral Resources of Zhejiang Province, 1989).

Although the stratigraphic orientation of ZMNH M8829 was not recorded in the field, the specimen includes several geopetal structures that indicate stratigraphic up and allow proper orien-tation. Further, preparation of the specimen at the museum assured the veracity of the skeleton-egg association. The speci-men consists of eggs and skeletal material preserved primarily within three blocks of red, very fine muddy sandstone (Fig. 1). All authors observed the specimen during preparation at the ZMNH. 

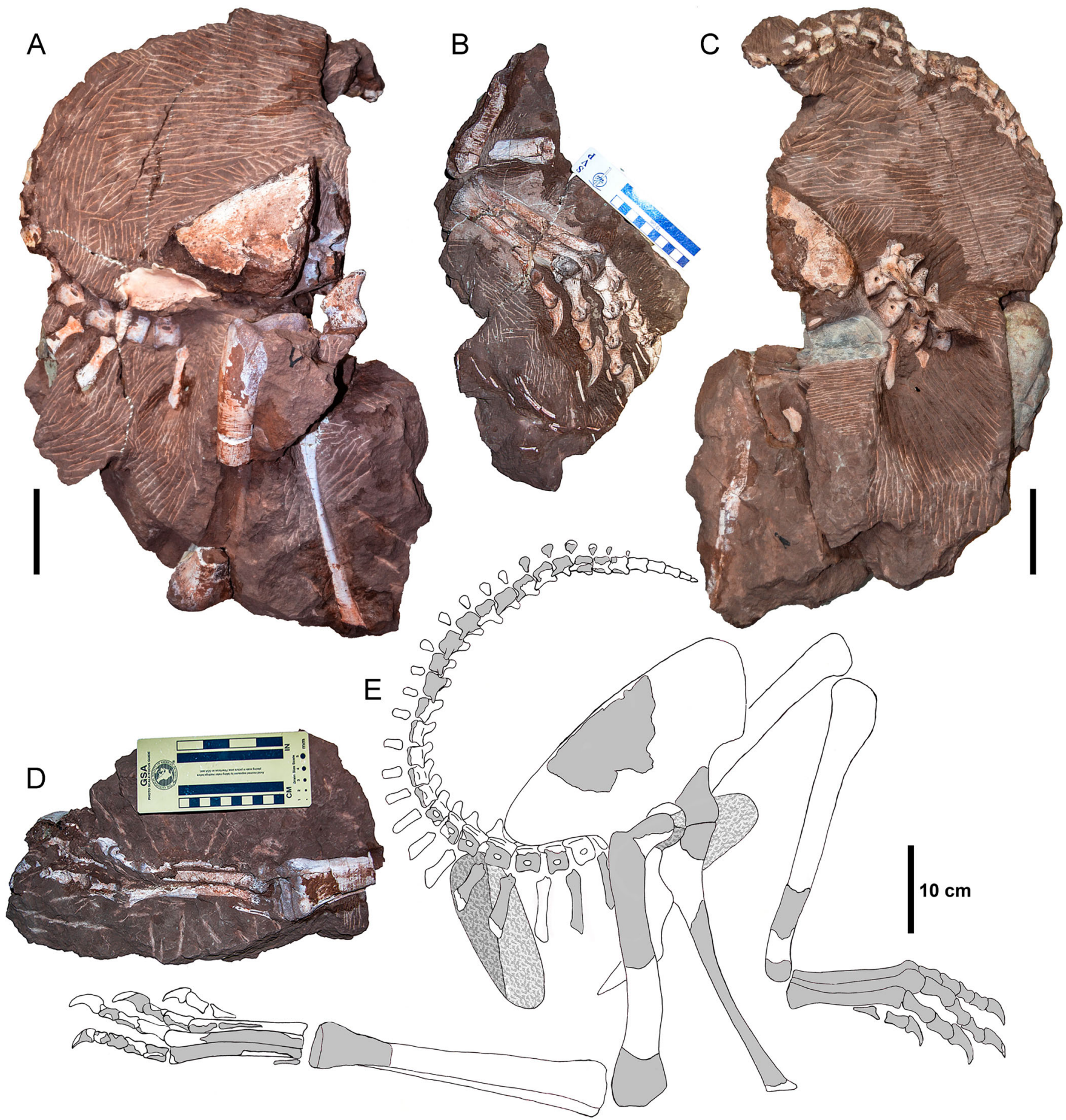

FIGURE 1. ZMNH M8829, an oviraptorosaur preserved in association with two eggs preserved in three blocks. A, major block in right lateral view containing portions of the pelvis and hind limb, tail, and two eggs. B, left pes in dorsal medial view with portions of the distal tibia and portion of the gastral basket. Presence of portion of the distal pubis allows positioning of this block relative to the major block. $\mathbf{C}$, major block as in $\mathbf{A}$, but in left lateral view. A portion of the internal egg is visible ventral to the ilium and anterior-most caudal vertebrae. Part of the external egg is visible more posteriorly. D, block containing articulated right pes and distal tibia and fibula in posterior view. $\mathbf{E}$, reconstruction of the skeleton in its hypothesized original orientation in map view with right side up. Gray shading and stippling represents visible bone and eggs, respectively. Scale bars equal $10 \mathrm{~cm}$.

\section{Histology}

Thin sections were prepared using standard paleohistological methods (e.g., Werning, 2012; Lamm, 2013). Samples were taken from the diaphysis of the right femur. Preservation precluded sampling at the exact midpoint of the diaphysis. Approximately the distal half of the diaphysis is absent, and the specimen retains only a negative mold of this portion of the femur. The sample was removed from the section of preserved 
bone closest to the midshaft, $13.5 \mathrm{~cm}$ from the proximal end. Although slightly proximal to the ideal sampling location, this area nonetheless lies outside the metaphyseal region.

The sample was embedded in Silmar-41 clear polyester resin (U.S. Composites). Slices were removed from the embedded block using a thin diamond blade Isomet low-speed saw (Buehler). Penetrant stabilizer (PaleoBond PB002) was added before premount grinding. Specimens were mounted using 2-ton epoxy (Devcon) and allowed to cure for 24 hours. Mounted slides were ground to optical clarity using increasingly fine paper from 120- to 1200-grit on the grinder/polisher.

Slides were examined and imaged using a D300 DSLR camera (Nikon) tethered to an Optophot2-Pol light transmission micro-scope. Filters permitted visualization of histological structures through enhanced birefringence. These included regular trans-mitted light (single polarizer), cross-polarized light, and ellipti-cally polarized light.

Bone tissue of ZMNH M8829 was further examined by inspect-ing postfossilization fracture surfaces of hind limb elements using a 20× hand lens and a low-angled light source. Magnification per-mitted observation of the medullary cavity, endosteal lamellar bone, secondary osteons, and vascular canals. Observations were made at 10.5, 13.5, and $25 \mathrm{~cm}$ from the proximal end of the $31 \mathrm{~cm}$ long right femur and sections $9 \mathrm{~cm}$ from the distal end of both tibiae.

\section{Eggshell Analysis}

Eggshell samples were removed from the two eggs, and half of each sample was prepared as a standard thin section (30 $\mu \mathrm{m}$ thick) using Epotek-301 as an embedding resin and Loctite Impruv 362 as the mounting adhesive and studied with a Nikon Eclipse polar-ized light microscope. Samples were taken from the middle sec-tions of both eggs, where lineartuberculate ornamentation predominates. Eggshell thin sections include ES 19, ES 474, and ES 475 from the internal egg and ES 369 and ES 528 from the external egg. The remaining half of each eggshell was coated with gold $(10 \mathrm{~nm})$, mounted on an aluminum stub, and imaged at $10-15 \mathrm{kV}$ with a JEOL 6100 scanning electron microscope (SEM) or a J. R. Lee Instrument personal SEM. The same pro-cedures were followed for eggshell from an oviraptorosaur associ-ated with eggs (IGM 100/979), used for comparison.

\section{Phylogenetic Analysis}

We conducted an analysis to assess the phylogenetic position of ZMNH M8829 following the analysis of Lamanna et al. (2014). With the addition of ZMNH M8829, this matrix contains 42 oper-ational taxonomic units (OTUs) and 230 characters. It was ana-lyzed using TNT (Tree Analysis Using New Technology) version 1.1 Willi Hennig Society edition using the gui interface (Goloboff, 2008). A traditional search (tree bisection-reconnec-tion swapping algorithm, 1,000 replicates, a random seed of 1,000, and 10 trees saved per replication) yielded 2,320 most par-simonious trees of 511 steps each. The addition of ZMNH M8829 did not alter the fundamental relationships recovered by Lamanna et al. (2014).

To test whether the addition of postcranial characters would improve our confidence in the position of ZMNH M8829, we ran a separate analysis using the matrix of Funston and Currie (2016). This matrix is based on that of Lamanna et al. (2014), to which they added a number of new characters and removed the ordered condition of several more.

\section{DESCRIPTION}

\section{Taphonomic Aspects}

ZMNH M8829 consists of a partial oviraptorosaur skeleton that is closely associated with two elongatoolithid eggs preserved within three blocks of fine sandstone (Fig. 1). Preserved portions of the skeleton include an incomplete pelvis, a sacrum, a nearly complete caudal series, and portions of both hind limbs. These elements remain in articulation except for displacement of the proximal tail away from the sacrum and portions of bones lost to modern erosion or during collection. A small number of articu-lated gastralia are the only other skeletal elements representing the adult.

Several geopetal features (discussed below) indicate that the carcass originally rested on its left side (Fig. 2). The tail is strongly arched, curling up and over the pelvis such that the last caudal vertebra lies well forward of the ilia. The right femur is retracted relative to the right pubis (Fig. 1). The knee bends at a right angle so that the right crus extends posteriorly with the foot lying plantar side up (Fig. 1D, E). In contrast, the left leg remains more folded, with its femur slightly protracted and the foot pro-jecting anteriorly, plantar side down (Fig. 1B, E).

The remnants of the gastral basket lie distal to the left foot (Fig. 1B). These include a series of arched elements lying with their concave aspect facing dorsally, i.e., toward the body cavity. The more posterior elements lie close to the distal termination of the pubes, in an anatomically consistent position. However, more anteriorly, the gastralia flare away from where the body cavity would have lain (Fig. 1).

One of the two eggs remains within the pelvic canal as formed by the sacrum, remnants of left and right ilia and ischia, and the right pubis, the missing portions having been lost to erosion and during collection. The long axis of the egg parallels the sacrum, with the blunt end of the egg extending to the first chevron between the second and third caudal vertebrae. One small (6 mm wide by ca. $50 \mathrm{~mm}$ long), unidentified, elongate, and arched bone lies anatomically dorsal to this egg (Fig. 2C). The second egg is posteroventrally positioned relative to the pelvis, with its long axis perpendicular to the internal egg. The blunt end of the external egg lies just beneath caudal 7 , with the remain-der extending below the chevrons associated with caudals 6 and 5.

Four geopetal features corroborate that the oviraptorosaur came to rest with its left side down (Fig. 2): (1) the right femur angles down (or toward the anatomical left) distally from its articulation with the acetabulum, and the remaining portions of the right limb all lie on a single horizontal plane (Fig. 2A); (2) the disarticulated proximal end of the tail lies below and to the left of the last sacral vertebrae, and the articulated caudal series extends slightly up and then down over the external egg before coming to rest on the same plane as the lower right leg; other elements, including the left tibia, fibula, and foot, and the gastra-lia, also lie on this same plane; (3) the egg within the pelvic region lies atop the left elements and away from those of the right side (Fig. 2C); and (4) the external egg exhibits asymmetric crushing, likely due to sediment loading, with a largely undamaged lower half and a more compressed and fractured upper half (Fig. 2B), an orientation pattern documented with other Cretaceous Chinese eggs (Wilson et al., 2014). Further, the distortion of the internal egg, as visible in its exposed cross-section, parallels the bedding plane interpreted for the specimen (Fig. 2C).

All bones are either in good condition with no evidence of weathering and scavenging or exhibit damage attributable to modern erosion and collection. The eggs, but not the bones, exhibit both internal and external blue-gray halos adjacent to the inner and outer surfaces of the eggshell. Inspection of the exposed broken portions of long bones with a $20 \times$ hand lens reveals simple hollow cross-sections, with no indication of medul-lary bone. 

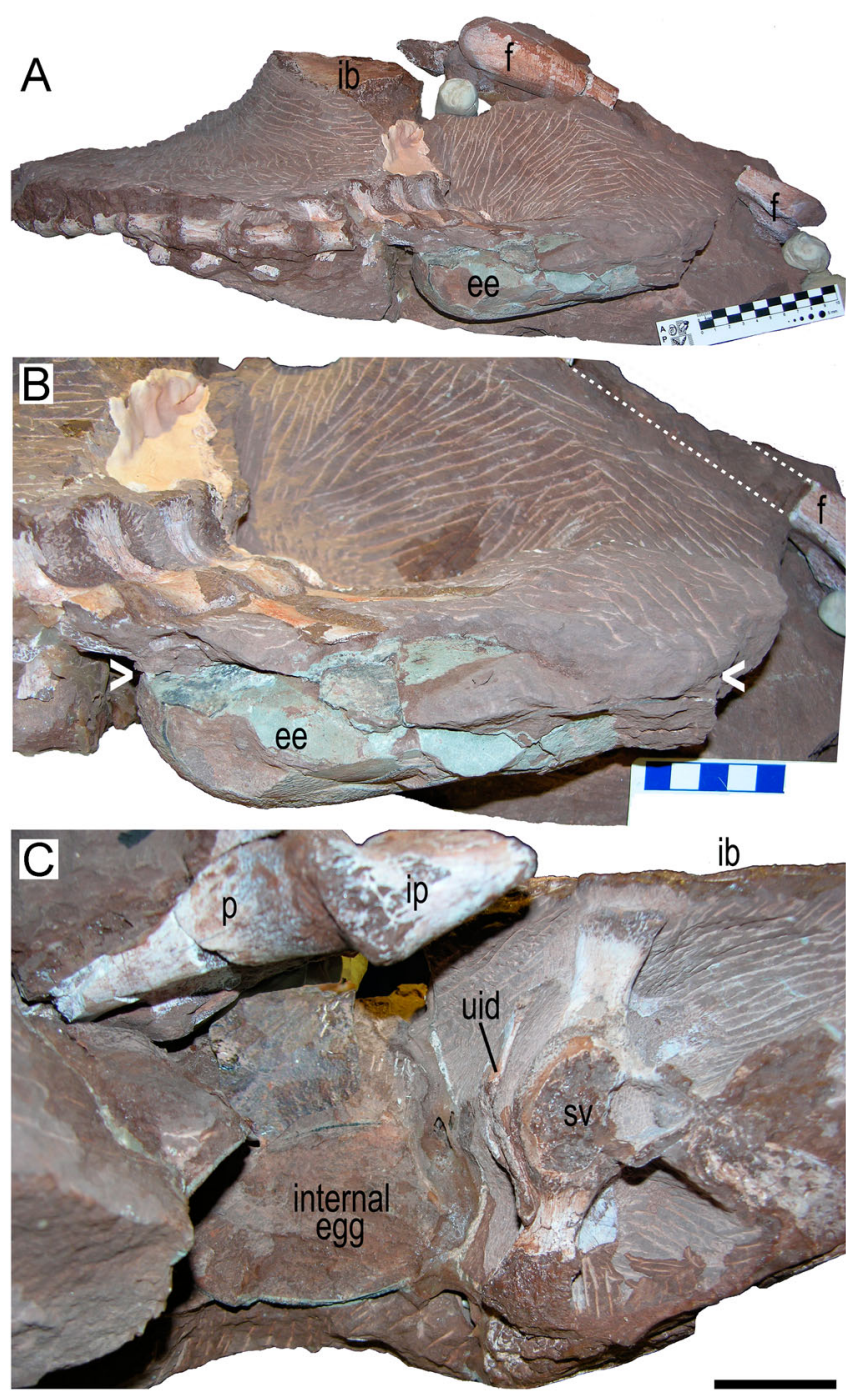

FIGURE 2. Features in ZMNH M8829 that provide geopetal information. $\mathbf{A}$, posterior view of the major specimen block that shows the animal on its left side, with the right femur angling down from its articulation with the right iliac blade to ground level where the caudal vertebrae lie. The external egg is visible ventral to the anterior caudal vertebrae and chevrons. B, similar view as in A showing external egg ventral to the anterior caudal vertebrae and chevrons, which lie on their left side. Plane of compaction of egg (marked by the white arrowheads) parallels plane defined by the tail. As typical for fossil eggs (Wilson et al., 2014), the stratigraphically upper portion has been flattened in comparison with the more naturally curved down side. The angled femur is seen in the background, with the missing shaft marked by dotted lines. $\mathbf{C}$, anterior view of pelvic canal showing the internal egg sitting along the left interior margin. The distortion to the normal circular cross-section of the egg also concurs with the animal coming to rest left side down. A small, unidentified bone sits just anatomically dorsal to the egg. Abbreviations: ee, external egg; f, femur; ib, iliac blade (right); ip, iliac peduncle; p, pubis (right); sv, sacral vertebra; uid, unidentified bone. Scale bars equal $10 \mathrm{~cm}(\mathbf{A}), 5 \mathrm{~cm}(\mathbf{B})$, and $3 \mathrm{~cm}(\mathbf{C})$.

\section{Skeletal Anatomy}

Vertebral Column-The specimen preserves no vertebrae anterior to the sacrum, which consists only of the last two sacral vertebrae. The penultimate is broken anteriorly and revealed in transverse cross-section. The vertebral body is dorsoventrally short, with a concave depression in the center of the dorsal surface within the neural canal. The convex ventral surface lacks a midline groove, giving the centrum an overall beanshaped cross-section (Fig. 2C). Two sacral ribs extend laterally from the sides of the exposed vertebra, widening toward their lateral contact with the ilia. An open line of suture, emphasized by damage to the cortical bone, occurs where they join with the sacral vertebra (Fig. 2C). The break, which lies anterior to the attachments of these ribs, may have followed the growth plate of the anterior face of the centrum. The last, largely obscured sacral vertebra provides few morphological details, but its shape conforms to that of the more anterior one in possessing a convex ventral face, lacking a groove. The line of fusion between the two vertebrae remains apparent.

A small, unidentified, boomerang-shaped bone about $65 \mathrm{~mm}$ long lies against the ventral surface of the sacrum (Fig. 2C). The bone curves at an oblique angle and maintains a fairly consistent width of 7.5-10 mm throughout its length. An oval hole in the upper side of this element appears taphonomic in origin. Identification of this bone remains problematic; it may represent a piece of rib, although the curve seems too abrupt to be the angle of the rib. A gastralium also seems unlikely because the gastralia in this specimen are much thinner and strut-like.

The tail is disarticulated from the sacrum, with the first caudal vertebrae displaced dorsally by about 4 or $5 \mathrm{~cm}$ from the last sacral. The well-preserved caudal series includes 26 vertebrae, with perhaps the last few posterior vertebrae missing. This is consistent with typical oviraptorid tails, which typically possess ca. 30 or fewer vertebrae (Barsbold et al., 2000; Persons et al., 2014). Unfortunately, we cannot say with certainty whether the tip of the tail possessed modified pygostyle-convergent vertebrae like those of oviraptorosauroids such as Nomingia (Barsbold et al., 2000), Anzu (Lamanna et al., 2014), Conchoraptor (Persons et al., 2014), and Citipati (Persons et al., 2014). The high vertebral count precludes a close resemblance to Nomingia, which has only 24 caudal vertebrae including the modified distal caudals (Barsbold et al., 2000). Pleurocoels are present on the lateral sides until at least the $23 \mathrm{rd}$ vertebra. This is a much higher proportion of pleuroceol-bearing caudals than the 11-18 reported for most Oviraptorosauria (Osmólska et al., 2004). The position of the pleurocoels in ZMNH M8829 resembles that of Jiangxisaurus (Wei et al., 2013), although only the anterior nine caudals are preserved in the latter specimen. In contrast, only anterior caudals of Anzu possess pneumatic foramina.

The centra of the caudal vertebrae range from large and rather anteriorly square to slightly more rounded but of similar proportions in the smaller posterior vertebrae (Table S1 in Supplemental Data). Transverse processes are present on at least the first 20 caudal vertebrae. The lines of fusion between the centra and the neural arches remain visible in all vertebrae. This suture zigzags and arches over ca. $3 \mathrm{~mm}$ above the large central pleurocoel. All centra possess large pleurocoels positioned laterally above the midline and below the line of suture with the neural arches (Fig. 3A, B). The pleurocoels of the first and second caudal vertebrae show a rounder outline than those of more distal caudals. The lateral pleurocoel of the first caudal forms a nearly perfect circle nestled within a deeper excavation. The second caudal has a shorter, squared-off foramen with a slightly longer ventral reach to its anterior edge. The first caudal uniquely bears a second slit-like pleurocoel on the lamina several millimeters in length, with the long axis oriented dorsoventrally (Fig. 3A). The second caudal exhibits a shallow depression in this same location.

The spinopostzygapophyseal laminae of the anterior caudals are stout and extend far posteriorly, thereby creating a deep central depression. The spinoprezygapophyseal laminae are similarly stout, although they do not sweep quite as far forward as their counterparts do posteriorly. However, they extend far enough forward to shelter a series of three to four small foramina on the neural spines. The thick, pyramidal neural spines are 

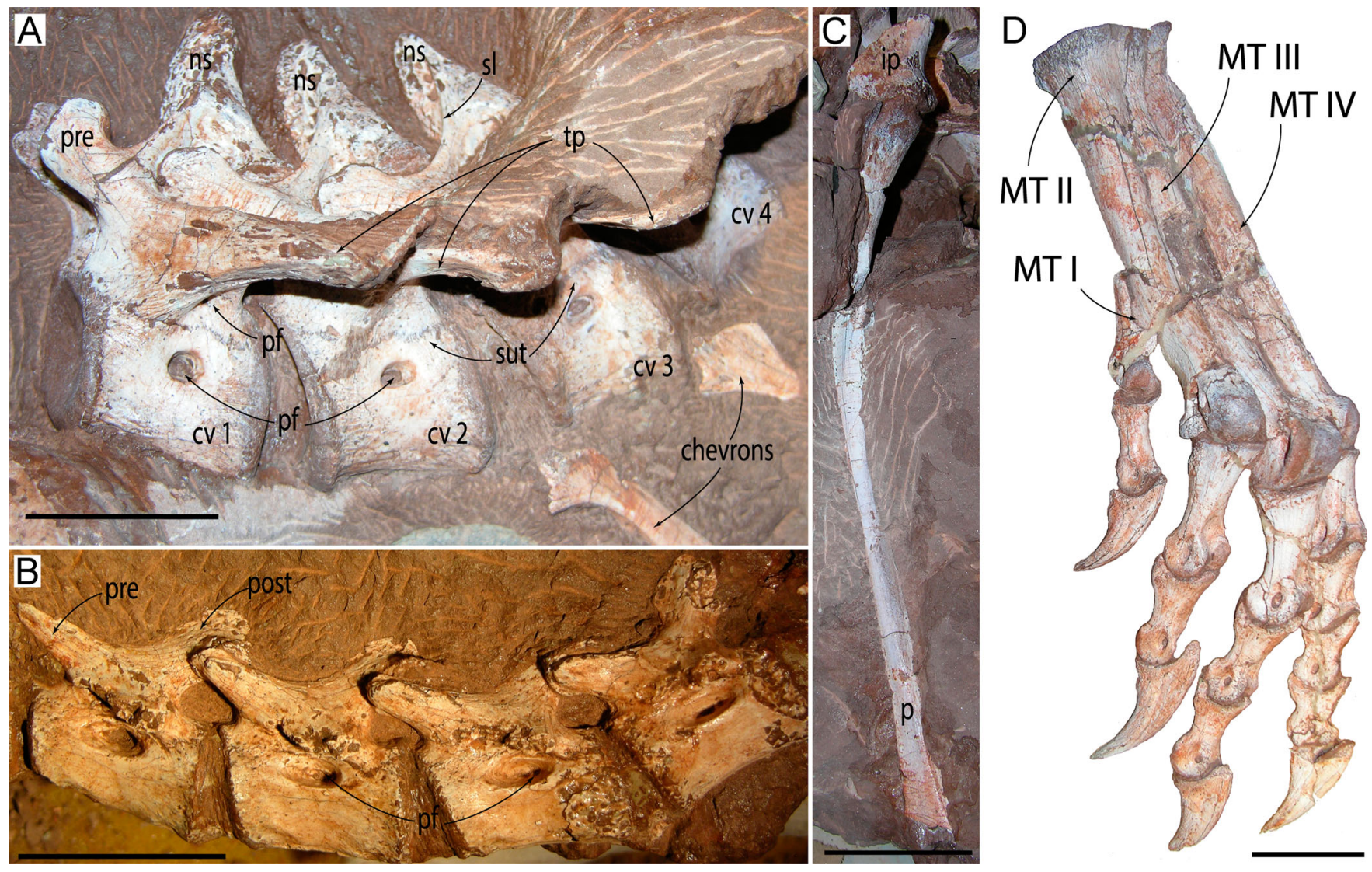

FIGURE 3. Morphological features of oviraptorosaur ZMNH M8829. A, anterior caudal vertebrae in lateral view. Note the persistent neurocentral sutures. B, mid-caudal vertebrae. C, right pubis in lateral view still articulated with peduncle of ilium. D, left pes in dorsomedial view. Abbreviations: cv, caudal vertebra; ip, iliac peduncle; ns, neural spine; p, pubis; pf, pneumatic foramina; pre, prezygapophysis; post, postzygapophysis; sl, spinoprezygapophyseal laminae; sut, suture. Scale bars equal $3 \mathrm{~cm}(\mathbf{A}, \mathbf{B}, \mathbf{D})$ and $5 \mathrm{~cm}(\mathbf{C})$.

highly pneumatized and largely reduced to a network of struts with a very thin cortical cover that is worn or absent in many cases. The anterior blade of the neural spine comes to a point and the zygapophyseal laminae rise dorsally nearly to the dorsal extent of the vertebrae, resulting in a pyramidal-shaped neural spine with a wide triangular lateral face. There appear to be several additional, pleurocoelous foramina in the vertebrae, variably expressed. Some of these may not fully penetrate the cor-tical layer and thus represent concavities.

The transverse processes of the anterior caudals are robust and triangular in anterior view, but rectangular and backward swept in ventral view. Two small openings along the backward sweep of the transverse process of the first caudal appear natural. The second and third caudals each preserve two small natural open-ings close to one another on the mid-ventral portion of the tri-angular face anterior to the transverse process.

The facets of the robust prezygapophyses are heart-shaped, with the point of the heart facing the neural canal. The larger upper lobe of the facet extends dorsally from the prezygapophy-sis, whereas the smaller lower lobe does not extend very far ventrally and only slightly anteriorly. The bottoms are slightly inclined medially. The postzygapophyses are only about half the length of the prezygapophyses, and their facets are more inclined.

ZMNH M8829 shares with all other oviraptorosaurs a tail that gradually transitions between proximal and distal caudals, lacking a distinct morphological demarcation (Osmólska et al., 2004). Where preserved, the sequentially smaller vertebrae have nor-mally positioned transverse processes projecting off of the central region of the neural arch directly above the single lateral pneumatic foramen.

Chevrons - The first caudal lacks a chevron, whereas chevrons in several other proximal vertebrae remain articulated. It remains unclear whether the absence of a chevron after the first caudal is anatomically or preservational. The fourth caudal also lacks a visible chevron. Those chevrons positioned behind the second and third caudals are visible on the animal's left side. The chevron following the third caudal has been prepared so that it is also visible on the right side of the specimen, where chevrons following the fifth and sixth caudals are also present. The last of these are broken distally, but adequately preserved to demon-strate the contact between the external egg and the skeleton. Importantly, the most anterior chevrons differ in shape from those more posterior. The visible anterior chevrons are flattened mediolaterally, elongate, and possess a ventral head with two articular facets that contact the two centra (Figs. $1 \mathrm{~A}, 3 \mathrm{~A})$. In con-trast to the first chevron that is strongly concave anteriorly, chev-rons $2-5$ display mild asymmetry that produces a slightly concave posterior aspect in lateral view (Fig. 1C). Additionally, in chevron 1, the angle between the proximal articular facets and the des-cending hemal spine is offset posteriorly, whereas in the following chevrons it rotates forward to be essentially straight (Fig. 1A). Another distinct difference is in the distal width of the ventral projection of the hemal spines. Unlike the finger-like projections found in most oviraptorosaurs (e.g., Balanoff and Norell, 2012), the distal ends of the proximal chevrons in ZMNH M8829 expand to form an anteroposteriorly oriented blade. This blade 
is widest in the fourth and fifth chevrons, which are damaged but nonetheless preserve a distal hemal spine twice the width of the narrowest portion. As in other oviraptorids (Osmólska et al., 2004), the posterior chevrons are dorsoventrally short and possess boot-shaped triangular profiles.

Gastralia-Several small bones lie among the left pedal pha-langes and to the medial side of the foot (Fig. 1B). We interpret these as posterior gastralia, only slightly removed from their expected position. They are all thin ( $3 \mathrm{~mm}$ diameter $)$ and frac-tured at both ends at lengths ranging from 25 to $>45 \mathrm{~mm}$. They lack articular ends but exhibit a curvature consistent with gastra-lia. They are disarticulated, their long axes broadly aligned with their concave edges toward the belly of the animal and parallel to the orientation of the phalanges.

Pelvic Girdle - Both ilia and ischia are partially preserved and embedded in the matrix supporting the skeleton; the pubes lack most of their distal ends. The short remaining portions of the ilia exhibit fairly straight dorsal margins until the posterior-most ca. $5 \mathrm{~cm}$ where there is a sharp downward turn. The postacetabular blade appears quite robust and has a maximum mediolateral thick-ness of nearly $2 \mathrm{~cm}$. The left side, however, preserves a strongly robust posterior edge that turns down sharply at almost $120^{\circ}$. The pubic peduncle of the right ilium remains in articulation with the proximal pubis. The peduncle is fairly narrow, although broken posteriorly, and only slightly thicker mediolaterally than the proximal pubis. The anterior ilium, including the cuppedicus fossa and the rest of the preacetabular process, is missing forward of the pubic peduncle. A small proximal portion of the pubic process of the right ischium remains in articulation with the pubis at the acetabulum. This does not include the shaft and does not extend far enough to preserve any portion of the obtura-tor foramen. The shaft of the right ischium, visible only in trans-verse cross-section, is slightly smaller than that of the pubis and strongly mediolaterally compressed.

Both pubes are preserved in articulation and surround the internal egg. The pubic shaft is strongly curved proximally as in some oviraptorids such as Nankangia (Lü et al., 2013) and Cor-ythoraptor (Lü et al., 2017) but straightens for the last three-quar-ters of its preserved length (Fig. 3C). The pubic shaft begins to flatten in its distal third, becoming laterally compressed and ante-roposteriorly broad toward the boot. If this represents the end of the shaft, then this condition is similar to that of Nomingia (Bars-bold et al., 2000). The overall shape of the pubis compares favor-ably with Khaan (Balanoff and Norell, 2012), but the distal curvature in Khaan is much greater than in ZMNH M8229.

Femur - The articulated right femur retains the proximal head and shaft and distal end separated by an impression of the distal diaphysis. The femur measures $31 \mathrm{~cm}$ in length and curves slightly posteriorly. The proximal end articulates with portions of the proximal pubis, pubic peduncle of the ilium, and a small part of the anterior curvature of the proximal ischium. A 2.8-cm section of the diaphysis remained in situ until sampled for his-tology (Fig. 4), and a 12-cm section is missing between this and the complete distal end (Figs. 1, 2A). The medial portion of this missing segment is preserved as a mold, allowing reliable measurements of total length and diameter and assessment of cur-vature. The diaphyseal diameter is $30.0 \mathrm{~mm}$ near the midshaft and remains constant along the length of the femur until widening in the last $40 \mathrm{~mm}$ to about $35 \mathrm{~mm}$ at the distal end. Although missing some cortical bone anterolaterally, the diameter of the epiphysis conforms to the end of the impression. Neither the bone nor impression shows evidence of a fourth trochanter.

The well-preserved proximal femur bears a distinct femoral head separated from the body of the femur by a clear neck. The anteroposteriorly compressed head appears less spherical than that of some other oviraptorosaurs, such as Gigantoraptor (Xu et al., 2007) or Khaan (Balanoff and Norell, 2012). In poster-olateral view, the broad greater trochanter has a smoothly curved

ventral extent. It is positioned lower than the femoral head and lacks any foramina. The lesser trochanter does not appear to extend above the line of the neck of the femur as in more basal coelurosaurs, e.g., Tyrannosaurus rex (Brochu, 2002). A very narrow fissure separates the greater trochanter from the medio-laterally thin and anteriorly strongly convex lesser trochanter. The ridge extending from the lesser trochanter down the anterior side of the femur is blade-like and recurved medially, forming a ' $\mathrm{J}$ ' shape in proximal view.

The distal femur has a distinct though relatively shallow patellar groove, medial compared with its position in Gigantoraptor (Xu et al., 2007). The strongly pronounced lateral epicondyle extends both distally and laterally beyond the body of the tibia. The smaller medial epicondyle projects mostly anteriorly, with a clear ridge running up the anteromedial surface of the distal femur. The medial surface of the distal femur is very flat and smooth. The inter-condylar groove is deep posteriorly, with an oval outline. Both the fibular and tibial condyles are slightly damaged; however, the incomplete cristatibiofibularis is prominent. A robust, blade-like crest extends proximally from the medial condyle.

Tibia, Fibula, and Tarsals - The proximal portions of both tibiae are missing, but the preserved distal portions remain in articulation with the feet. The medial malleolus extends distally ca. $0.5 \mathrm{~cm}$ farther than the lateral malleolus and appears medially flattened.

The fibula, where preserved distally, is reduced to a thin splint, only $1-1.5 \mathrm{~mm}$ thick, representing perhaps $1 / 15$ to $1 / 20$ of the anteroposterior width of the tibia. The fibula appears to extend fully to the base of the tibia to contact the tarsals, based on obser-vation of the right hind limb (Fig. 1D).

Both sets of proximal tarsals are articulated. The right and left astragali are visible in posterior view and in medial view, respect-ively. The tall ascending process of the left astragalus extends at least $80 \mathrm{~mm}$ above the articular surface of the ankle. The proximal tarsals of the right foot appear unfused and slightly separated by a thin layer of matrix, but further details of the calcaneum are obscured by matrix.

Metatarsals and Phalanges - Both left and right pes are well preserved, although some elements of the right pes are eroded. The more complete left pes preserves metatarsals I-IV with all phalanges of the four digits articulated and visible along their complete lengths. The right metatarsal I (MT I) is medially expanded to a scalloped edge, a feature more irregular than in other known oviraptorosaur feet, including those of Ganzhosaurus (Wang et al., 2013) and Khaan (Balanoff and Norell, 2012). The left MT I also has a pronounced anterodistal expansion but is incompletely preserved. The distal articular surface of MT I is large, triangular in dorsal view, and extends far back on the shaft, implying a great degree of poss-ible extension at the phalangeal joint. Metatarsals II-IV (MTs II-IV) appear relatively shorter than in other oviraptorids (Table S2), although an accurate comparison with the complete tibia length remains impossible. MTs II and IV are robust and broad in comparison with that of the narrower MT III, which is only 5 mm wide at its proximal end, as opposed to MT II, which measures $18 \mathrm{~mm}$ wide at its proximal end. Metatarsals II-IV exhibit similar lengths, with MT III marginally the longest and MT IV only a few millimeters longer than MT II. The distal heads of MTs II and IV are hemispherical in lateral and medial views, respectively. The articular surfaces of the distal condyles extend onto the medial portion of MT II and the lateral portion of MT IV. In contrast, the fairly flat articular surface of MT III is nearly twice as mediolaterally wide as those of the other two metatarsals and is confined to the distal end of the bone, with only a minor medial depression. Although the plantar surface remains partially obscured by matrix, the distal articulation of MT III appears weakly ginglymoid. The lateral ligament fovea at the distal end of MT III exhibits a diameter more than twice that of MT II. 
A
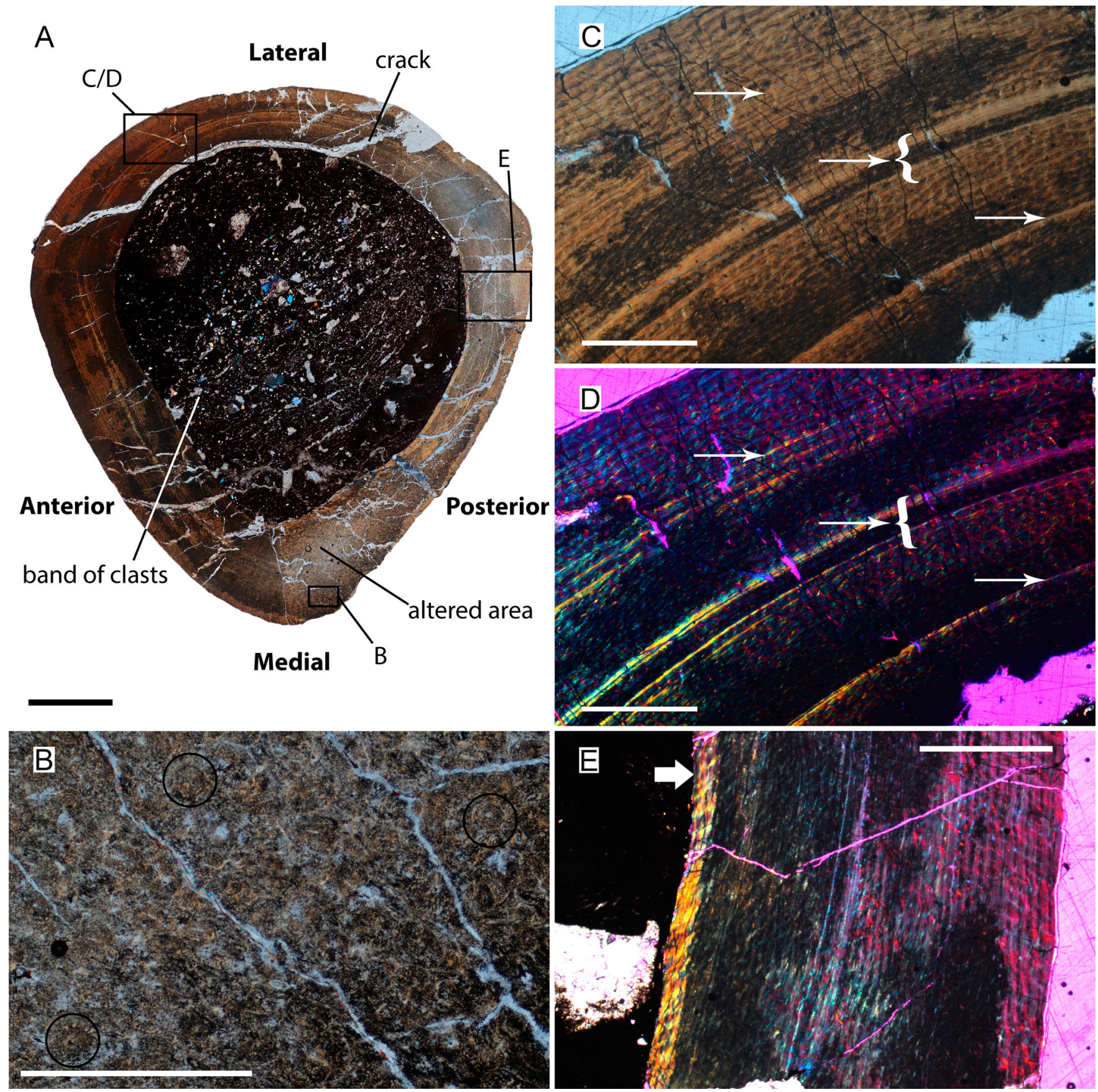

FIGURE 4. Osteohistology of oviraptorosaur ZMNH M8829. A, cross-section of mid-diaphysis of femur. Boxes indicate positions of detailed photographs in $\mathbf{B}-\mathbf{E}$. B, detail of $\mathbf{A}$ showing bone degradation at medial apex; note remnants of secondary osteons (circled). $\mathbf{C}$, anterolateral detail of $\mathbf{A}$ showing primary cortical tissue; exterior to upper left; note three LAGs (arrows); second LAG is diffuse, indicated by bracket. D, same as C but taken through first order retardation plate ( $1 / 4$ lambda tint plate). E, posterior detail of $\mathbf{A}$ under elliptically polarized light. Note differing birefringence of lamellar endosteal bone on interior of cortex (thick arrow). Scale bars equal $5 \mathrm{~mm}(\mathbf{A})$ and $1 \mathrm{~mm}(\mathbf{B}-\mathbf{E})$.

MT V is fractured and retains few discernible details. The break exposes cancellous bone proximal to a small, open medullary cavity. The gracile element is only $4 \mathrm{~mm}$ wide, and its length is less than one-third that of MT IV.

The phalangeal formula of 2-3-4-5 corresponds to the typical theropod condition. The relatively long phalanges are more gracile than in other taxa, such as Wulatelong (Xu et al., 2013). The large pedal unguals are only slightly curved, but more so than in Heyuannia (Lü, 2002), Khaan (Balanoff and Norell, 2012), and Anzu (Lamanna et al., 2014).

The dorsoventrally shallow unguals also differ from $A n z u$, which has a deep, short ungual morphology similar to that in Gigantoraptor (Xu et al., 2007). In contrast to the distinct dorsal and ventral blood grooves of Gigantoraptor, the unguals of ZMNH M8829 possess a single groove with a broader surface, deepening distally. The second ungual slightly exceeds the others in size but is not sub-stantially larger as in Deinonychosauria. This mild enlargement of the second digit may help distinguish this taxon from Khaan, 
for which Balanoff and Norell (2012) found no evidence of ungual size difference.

Histology - The uncrushed right femur retains the original dimensions of the shaft with a rounded, triangular cross-section. Calcite-filled cracks are present around the circumference of the bone and predominately extend radially, with the exception of one large fracture that breaks through the cortex on the lateral side to run circumferentially along the endosteal surface (Fig. 4A). Oxidized sediment indistinguishable from the country rock fills the medullary cavity. Clasts of up to a $2 \mathrm{~mm}$ are intermixed with the infilling matrix. No clear sedimentary structures are visible, although there does appear to be a preferential orientation of linear clasts in a band extending from the anteromedial to the posterolateral side of the medullary cavity. In a few places, especially medially, the calcite-filled cracks appear to continue into the matrix. No cancellous bone is present (Fig. 4A). Throughout the cortex, sections of bone show evidence of taphonomic alteration. In these areas, the bone appears darker in color, is largely opaque, and lacks birefringence and details of osteocyte lacunae, canaliculi, and even osteons (Fig. 4B). Other authors have attributed similar patterns of alteration to the activity of bacteria or fungi (e.g., Werning, 2012). This renders parts of the bone difficult to interpret. Intriguingly, the degradation appears more prevalent in the areas with the most secondary osteons (Fig. 4B).

Bone deposition appears uniform, with little secular change radially from the endosteal to the periosteal surface. The pattern of vascularization is laminar/subplexiform throughout, with most of the primary osteons longitudinally oriented and confined to circumferentially arranged bands (Fig. 4C-E). The majority of visible Volkmann's canals extend circumferentially between these primary osteons, rather than anastomosing radially. The highly laminar organization of the cortical vascularization suggests relatively high growth rates (Castanet et al., 1996). The cortex consists predominantly of fibrolamellar tissue, with minimal woven-fibered bone. Secondary osteons are concentrated mostly in the medial, posterior, and anterior regions, consistent with muscles attaching in these directions (Currey, 2002). These same areas are the most altered, possibly from bacterial or fungal invasion, and therefore difficult to characterize. Nevertheless, the circular outlines of the secondary Haversian systems remain visible in some areas.

Three lines of arrested growth (LAGs) occur within the existing cortical bone. The middle LAG is composed of two to three closely spaced annuli and an additional annulus slightly offset endosteally to the others (Fig. 4C, D). The innermost LAG is a double LAG, with two lines distinguishable in parts of the bone's circumference. The fibrolamellar bone continues evenly to the periosteal surface where there is no evidence of an external fundamental system or other signals of cessation of radial growth.

The inner surface of the cortex of M8229 does not preserve continuous, finished, lamellar endosteal bone. Small amounts of endosteal bone occur in isolated packets, some of which (e.g., on the posterior lateral side of the medullary cavity) show moderate thickness and extent. Under elliptically polarized light, the remnant endosteal bone is visibly parallel-fibered, with a lamellar organization of the collagen fibers (Fig. 4E). Where preserved, the inner surface of this tissue is rough, irregular, and cuts across the lamellae. Distinguishing between the possible origins of this eroded inner surface remains problematic, but it may simply be a product of medullary cavity drift. Few, if any, erosion rooms are present in the inner cortex, and in at least one place the endosteal edge cuts across some secondary Haversian systems. There is no medullary bone present.

\section{Eggs and Eggshell Microstructure}

Internal Egg - Neither egg is adequately exposed to provide a complete set of measurements nor a full examination of ornamentation. The internal egg exhibits lineartuberculate ornamentation over most of its length that becomes more nodose at the pole. A fracture exposes the egg in transverse cross-sectional view where it measures $90 \mathrm{~mm}$ in diameter in a horizontal plane and $47.7 \mathrm{~mm}$ vertically. This suggests a significant amount of compaction. The eggshell thickness varies from 595 to $1245 \mu \mathrm{m}$ depending on height of the ornamentation and the individual sample. Radial thin sections and SEM imaging of ES 319 reveal two structural layers of calcite, a 519- $\mu$ m-thick mammillary layer (ML) and a 670 - $\mu$ m-thick continuous layer (CL), with a ML:CL ratio of 1:1.3 (Fig. 5A-C). A relatively straight (rather than undulating) contact separates the two layers. The inner mammillary layer consists of narrow, closely packed, elongate mammillary cones that average about $127-225 \mu \mathrm{m}$ in diameter (Fig. 5D). The radiating crystallites that constitute the cones originate from nucleation sites at the inner surface of the eggshell. These calcite nuclei are typically intact and well preserved (Fig. 5D), although some eggshells show pressure dissolution that likely results from contact with quartz grains in the surrounding matrix. Approximately $250 \mu \mathrm{m}$ above the nucleation sites, the radiating spherulites of the mammillae are no longer apparent and the crystalline structure displays a blocky appearance (sensu Jin et al., 2007) (Fig. 1A, B, D). The overlying continuous layer exhibits horizontal or gently undulating accretion lines that weakly follow the ornamentation. Some eggshell samples (ES 475 2A) show greater calcite recrystallization, as well as delamination of the surface ornamentation (Fig. 5E). Thin sections viewed under crossed Nicols exhibit sweeping extinction in less altered areas of the eggshell. A tangential section shows round to subrounded pores that measure 12-26 $\mu \mathrm{m}$ in diameter. Alteration of the eggshell prohibits confident identification of all pores and therefore prevents accurate assessment of pore density.

External Egg - The asymmetric external egg measures $190 \mathrm{~mm}$ long. Crushing created an irregular plane of fractures paralleling the plane containing the series of caudal vertebrae. As with the internal egg, linear ridges of the ornamentation align with the long axis of the egg. The 1,091- $\mu$ m-thick eggshell (ES 369) exhibits two structural layers: a 456- $\mu$ m-thick mammillary and a $635-\mu \mathrm{m}$-thick continuous layer (Fig. 6A). The mammillary cones are ca. 120-215 $\mu \mathrm{m}$ wide, and the calcite nuclei are typically absent. The contact between the mammillary and the continuous layer appears relatively distinct and straight to slightly undulating. In scanning electron photomicrographs, prominent radiating crystals are visible in the basal part of the mammillary cones and the contact with the overlying continuous layer is less apparent than in standard thin sections (Fig. 6B). In some areas, 'lenses' of blocky crystals occur in the upper portion of the mammillary layer, and these features exhibit relatively distinct boundaries, similar to that of the ML-CL contact (Fig. 6A). Eggshell thickness and proportions of the mammillary and continuous layers differ among eggshell samples, likely due to differences in sample location on the egg, eggshell alteration, and greater weathering of some fragments.

Comparisons-The internal and external eggs in $\mathrm{ZMNH}$ M8829 exhibit similar eggshell thickness and microstructure, with a ML:CL ratio of $1: 1.3$ to $1: 1.4$. The eggs are referable to the Elongatoolithidae on the basis of their elongate shape, twolayered eggshell structure, narrow and closely spaced mammillae, lack of visible prisms in the continuous layer, and lineartuberculate, nodose, and dispersituberculate ornamentation (Zhao, 1975; Mikhailov, 1991, 1997).

The Elongatoolithidae includes the oogenera Macroelongatoolithus, Elongatoolithus, Trachoolithus, Macroolithus, and Nanhsiungoolithus (Mikhailov, 1997). Eggs of the last oogenus are rare and the eggshell structure inadequately illustrated (Mikhailov, 1997). Egg size largely distinguishes the remaining four oogenera from each other. Macroelongatoolithus vary from about 25 to over $50 \mathrm{~cm}$ in length, thus excluding the eggs of ZMNH M8829 from this oogenus. Elongatoolithus and Trachoolithus are less than $17 \mathrm{~cm}$, whereas the diagnosis for Macroolithus 

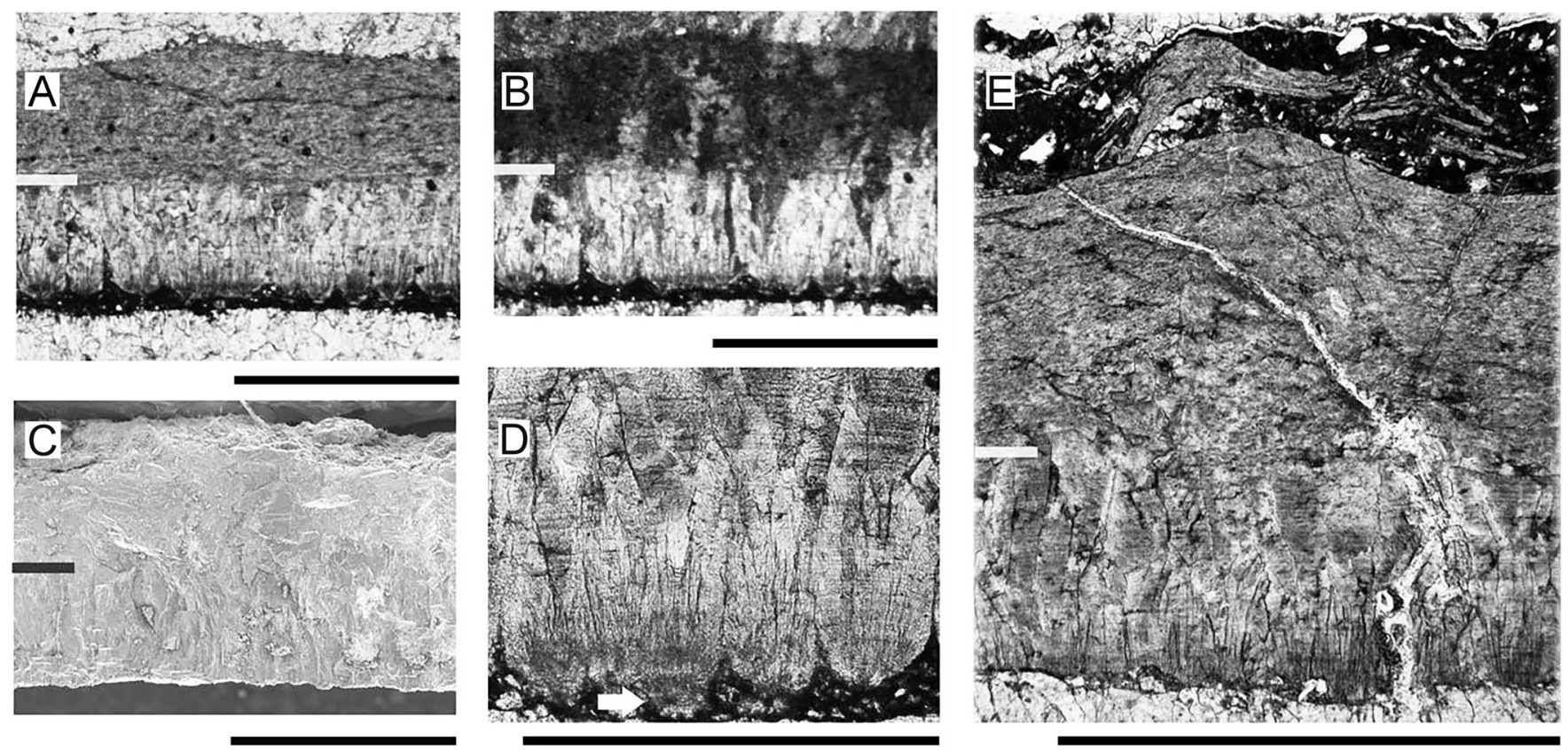

FIGURE 5. Structure of internal egg from ZMNH M8829. A, eggshell in radial thin section under plane-polarized light. B, same as A under crossed Nicols. C, SEM of eggshell from same egg. D, enlargement of mammillary cones in $\mathbf{A}$; arrow indicates intact nuclei. E, eggshell (ES 475) showing delamination of the surface ornamentation; fracture extends across entire eggshell thickness. Outer eggshell surface is at the top of each image. White bars in $\mathbf{A}, \mathbf{B}$, and $\mathbf{E}$ indicate contact between the mammillary and continuous layers; gray bar in $\mathbf{C}$ indicates same. Scale bars equal $1 \mathrm{~mm}(\mathbf{A}-\mathbf{C}, \mathbf{E})$ and $500 \mu \mathrm{m}$ (D).

indicates that they range from 16.5 to $21 \mathrm{~cm}$ in length (Zhao, 1975; Carpenter, 1999). The $19 \mathrm{~cm}$ length of the external egg of ZMNH M8829, together with the typical elongatoolithid microstructure, suggests that the eggs likely belong to the oogenus Macroolithus.
Elongatoolithid eggs directly associated with oviraptorosaur adults and embryos represent several ootaxa, including Elongatoolithus, Macroolithus, and Macroelongatoolithus (e.g., Dong and Currie, 1996; Clark et al., 1999; Sato et al., 2005; GrelletTinner et al., 2006; Weishampel et al., 2008; Wang et al., 2016;
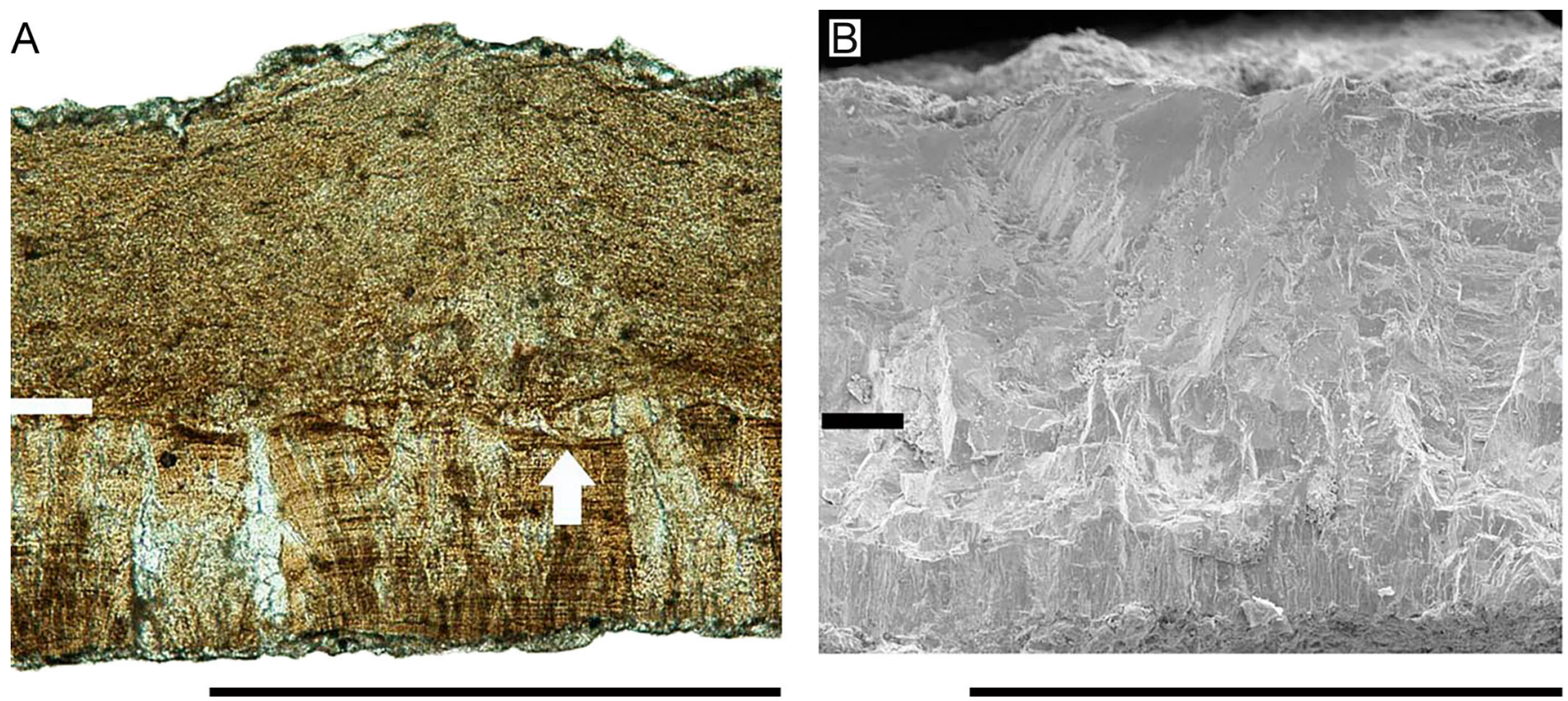

FIGURE 6. Structure of external egg from ZMNH M8829. A, eggshell in radial thin section under plane-polarized light. Arrow points to blocky crystal lens in the upper mammillary layer. White bar indicates contact between the mammillary and continuous layers. B, SEM image of same. Note prominent calcite spherulites of the lower mammillary layer, compared with more altered structure in the upper portion of the same layer. Scale bars equal $1 \mathrm{~mm}$. 
Pu et al., 2017), See Simon et al. (2019) for a review of these eggs associated with embryonic or adult skeletal material. The eggs preserved in ZMNH M8829 compare most favorably with those associated with IGM 100/979, an adult Citipati osmolskae that overlies an unhatched egg clutch (Clark et al., 1999), and others, both from the Nanxiong Formation, potentially assigned to Macroolithus yaotunensis (Sato et al., 2005; Wang et al., 2016). Sato et al. (2005) described an adult oviraptorosaur with two elongatoolithid eggs within the body region and noted similarities between their specimen and M. yaotunensis. Similarly, Wang et al. (2016) more recently described eggs with embryos and also considered them to be similar to M. yaotunensis. All of these eggs, including those of ZMNH M8829, are 17-19 cm long and have eggshell thicknesses of ca. 1.0-1.2 $\mathrm{mm}$ (Table 1). The possible M. yaotunensis eggs (Sato et al., 2005) also have the closest ML:CL ratio, $1: 2$, to the $1: 1.4$ ratio of $\mathrm{ZMNH}$ M8829. Our measurements of eggshell from Citipati eggshell, IGM 100/979, yield mammillary and continuous layer thicknesses of 357 and $613 \mu \mathrm{m}$, respectively, with total shell thickness of 970 $\mu \mathrm{m}$. The ML:Cl of 1:1.7 of this eggshell is somewhat higher than in ZMNH M8829. However, Grellet-Tinner et al. (2006) discuss several eggs associated with adult oviraptorosaurs (IGM 100/ 979, IGM 100/1004, and IGM 100/1125), including the Citipati specimen. They report thinner eggshell ranging from 500 to 641 $\mu \mathrm{m}$, with a $169-\mu \mathrm{m}$-thick mammillary and a $402-\mu \mathrm{m}$-thick continuous layer. The thicknesses of these oviraptorosaur eggshells are less, whereas the ML:CL ratio (1:2.4) exceeds that of eggs from ZMNH M8829. Other eggs containing oviraptorosaur embryonic remains are more difficult to compare with ZMNH M8829 because of the incomplete nature of the specimens and therefore the absence of original egg length (Norell et al., 1994; Weishampel et al., 2008). Overall, the eggs most similar to those of ZMNH M8829 also come from the Upper Cretaceous Nanxiong Formation of Jiangxi, China, and are likely assignable to M. yaotunensis.

\section{DISCUSSION}

\section{Taxonomic Placement}

Preservation of only the posterior half of ZMNH M8829 complicates taxonomic identification. The newly named Tongtianlong is poorly preserved behind the pectoral girdle due to damage during collection (Lü et al., 2016). The holotype includes a pes similar to ZMNH M8829 in almost all respects and shares the concave shape of the distal astragalus. Only a few elements overlap with the recently named Jiangxisaurus (Wei et al., 2013), including proximal caudals in ventral view and undescribed fragmentary pelvic remains. Both taxa share short, wide proximal caudal vertebrae with dorsally located pleurocoels, features common to oviraptorosauria and not diagnostic. Consequently, the overlapping elements do not preclude the two specimens from being the same taxon. Other Nanxiong oviraptorids, including Huanansaurus (Lü et al., 2015) and Banji (Xu and Han, 2010), share little to no overlapping material with $\mathrm{ZMNH}$ M8829. More comprehensive comparisons, therefore, must await the fuller description of these elements or new discoveries of oviraptorids from Jiangxi Province.

Other described oviraptorosaurs share more overlapping material, facilitating better comparisons. Femoral and caudal anatomy is similar to that of Nankangia (Lü et al., 2013), but ZMNH M8829 lacks the distinctive infraprezygapophyseal fossa present on the lateral surface of the anterior caudals of this taxon. The large process of the lesser trochanter has a more blade-like shape than the 'finger-like' trochanter of Nankangia. Only cranial features provide diagnostic characters for Wulatelong (Xu et al., 2013), and comparison with the postcrania of this skeleton is difficult due to its generally poor state of preservation. The pes provides the best comparisons: ZMNH M8829 shares a proximally compressed MT III with Wulatelong, a feature also present in Khaan (Balanoff and Norell, 2012) and purportedly shared with stem oviraptorosaurs (Xu et al., 2013). However, the feet of ZMNH M8829 have an MT II and an MT IV equal in size, unlike in Wulatelong where MT II is smaller. ZMNH M8829 shares a straight pubic shaft with caenagnathids such as Anzu (Lamanna et al., 2014). Although incomplete, the remaining portions of the pubis distinguish the specimen somewhat from a previous oviraptorosaur discovered with eggs (NMNS VPDINO-2002-0901; Sato et al., 2005) from the Nanxiong Formation, which has an anteriorly curving pubic shaft with a more distal inflection point and a relatively larger diameter than ZMNH M8829.

The morphology of the pubis, the caudal vertebrae, and the relative dimensions of the pes compare well with material from the recently identified cloud of oviraptorids from the Nanxiong Formation of Jiangxi and Guangdong provinces. These similarities suggest oviraptorid affinities, consistent with the abundance of the clade in the Upper Cretaceous of southern China. The absence of cranial features prohibits a more definitive assessment.

Phylogenetic analysis recovered ZMNH M8829 as the sister taxon to the Caenagnathoidea, a group composed of Caenagnathidae and Oviraptoridae. However, the incompleteness of the specimen and the distribution of the missing data (i.e., absence of cranial or forelimb material) likely contribute to the placement of this specimen in an earlier-diverging position. In the Lamanna et al. (2014) matrix, $60 \%$ of the characters concern cranial and mandibular elements. Fewer than onequarter correspond to elements present in ZMNH M8829 and not all of these are visible for scoring. If the condition of hind limb and caudal characters in ZMNH M8829 are relatively plesiomorphic, this may generate a suspect basal position in the phylogeny. Refinement of the oviraptorosaurian phylogeny may test this possibility, especially with the inclusion of more postcranial characters. Using the matrix of Funston and Currie (2016) did not result in a clearer position for the specimen. Rather, a strict consensus resulted in a collapse of Caenagnathidae into a polytomy that includes ZMNH M8829. As to why this tree resulted in the collapse of the clade, we do not speculate but note that many of the characters record autapomorphies in Elmisaurus or a small number of allied Caenagnathids.

\section{Taphonomy}

The posture of the skeleton and the close position of the eggs in ZMNH M8829 suggest that the eggs belong to the associated individual. The skeleton retains a pose common to many Mesozoic theropods, lying on its side with recurved tail over the back and splayed hind limbs. This specimen may fit the opisthotonic posture of Faux and Padian (2007). This posture, combined with the high degree of articulation, suggests an absence of hydraulic modification. The position of the two complete eggs, one within the pelvic canal and the other just posterior to it near the presumed cloaca and draped in part by the proximal chevrons, argues strongly that they belong to the adult and were neither consumed nor washed in. A specimen of the pterosaur Kunpengopterus retains two eggs in nearly the same arrangement (Wang et al., 2015). Further, the arrangement of the eggs relative to the skeleton parallels the occurrence of young that lie partially exiting and external to adult ichthyosaurs and other marine reptiles (Böttcher, 1990; McGowan, 1991; Motani et al., 2014). The adult may have perished just after laying one egg, but more likely the eggs were partially to fully extruded by postmortem gases associated with internal decay built up inside the coelom. We have observed similar extrusion of young in a drowned, pregnant cow (Fig. 7). This same process has been hypothesized as the cause of the full and partial expulsion of ichthyosaur young from Holzmaden 
TABLE 1. Comparison of some eggs and eggshell associated with adult or embryonic oviraptorosaurs.

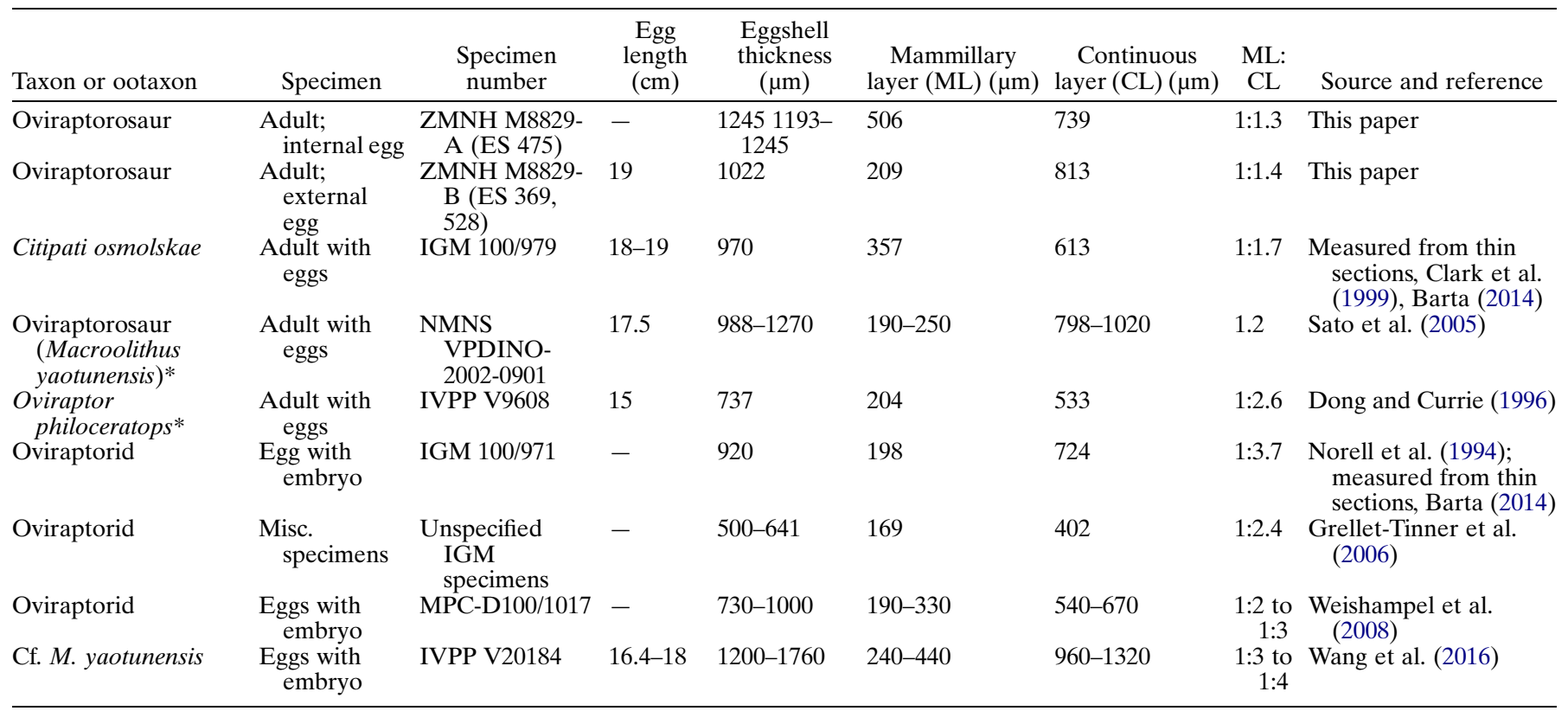

*Measurements from published figure.

adult specimens (Böttcher, 1990; McGowen, 1991). The displaced anterior portion of the gastral basket likely also reflects the distension and rupture of the abdominal cavity, consistent with decayassociated carcass bloat. Alternative interpretations, e.g., that the external egg is associated merely by chance with the adult, seem unlikely. Nor does it appear that the external egg belongs to a previously existing clutch, because it lacks a close neighbor as typically found in the elaborate tight rings of oviraptorosaur clutches (Clark et al., 1999) and there are no signs of any additional eggs in the three blocks.

One small isolated bone exists within the pelvic canal in a position anatomically dorsal to the egg. This element may simply represent a displaced sacral or posterior dorsal rib. However, the overall shape seems inconsistent with both. Potentially, this bone may represent a digested element that, like the egg, was being forced out of the body by the buildup of internal gases, because the large intestine would lie just dorsal to the reproductive tract before converging in the cloaca.

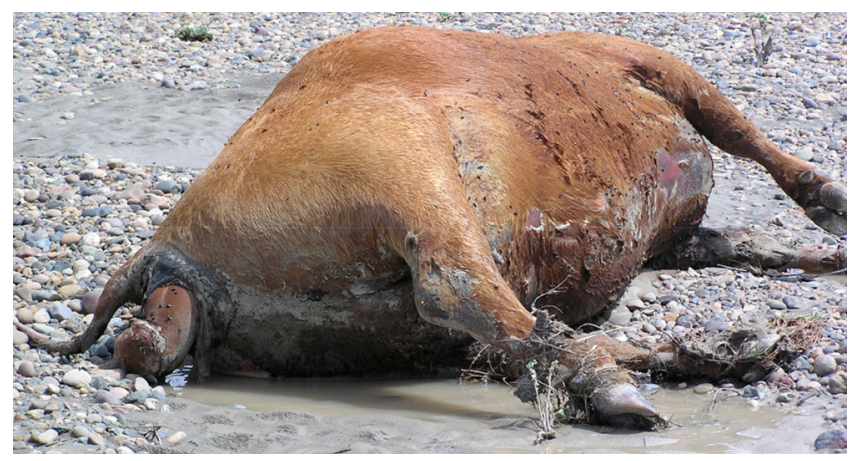

FIGURE 7. Extrusion of calf out of drowned cow along Yellowstone River, Montana.

\section{Reproductive Implications}

Monoautochronic ovulation, the production of one egg from each ovary and oviduct simultaneously at daily or greater intervals (Smith et al., 1973), was hypothesized to represent an intermediate step between more primitive en masse laying from two reproductive tracts and the iterative laying of a single egg from a single functional ovary and oviduct in birds (Varricchio et al., 1997). Non-avian maniraptorans would iteratively produce two eggs from two avian-like reproductive tracts (Varricchio et al., 1997). First hypothesized for oviraptorosaurs and troodontids by Varricchio et al. (1997) based on within-clutch egg pairing, monoautochronic ovulation was later supported by the presence of two eggs within the rib cage of an oviraptorosaur (Sato et al., 2005). The presence of two eggs with a similar level of development in ZMNH M8829 provides further support for monoautochronic ovulation. The narrow fit of the egg in the pelvic canal argues against the hypothesis that theropods laid eggs in bound pairs (Li et al., 1995; Larson, 1998).

The iterative style of laying resulting from monoautochronic ovulation may have allowed production of larger eggs relative to adult body mass, because birds produce far larger eggs relative to adult mass than reptiles (Blueweiss et al., 1978). The overall size of the eggs in this oviraptorosaur, relative to the adult mass, is consistent with hypothesis. Using the egg dimensions (190 mm long with cross-section $47.7 \times 90 \mathrm{~mm}$ ) and the equation of Hoyt (1979), the estimated egg mass is $500 \mathrm{~g}$. Based upon the femur circumference with diameters of $31.2 \mathrm{~mm}$ and $33.4 \mathrm{~mm}$ and the equations of Anderson et al. (1985) and Campione et al. (2014), adult weight is estimated at $47.4 \mathrm{~kg}$ or $69.7 \mathrm{~kg}$, respectively. By the equation of Blueweiss et al. (1978), birds of these adult masses are predicted to produce a single egg weighing 1,040 or $1,390 \mathrm{~g}$. Thus, as noted by Varricchio and Jackson (2004), the iterative production of two eggs by these Mesozoic maniraptorans is on par with the reproductive output of extant birds as measured by net weight.

The two internal eggs described by Sato et al. (2005) in another Jiangxi oviraptorosaur are oriented with their narrow end 
pointing toward the pelvic canal. This orientation concurs with egg formation in modern birds, where the pointed end is caudad (Olsen and Byerly, 1932; Gill, 1989; Salamon and Kent, 2014). Although some evidence suggests that there is a $180^{\circ}$ rotation an hour prior to laying to reorient the egg into a blunt-end-first position (Bradfield, 1951), most birds appear to lay their eggs pointed end first (Olsen and Byerly, 1932; Wood-Gush and Gilbert, 1969; Salamon and Kent, 2014). In contrast, the two eggs associated with ZMNH M8829 sit having exited or about to exit the cloaca blunt end first. This blunt-end-out arrangement may simply reflect the postmortem extrusion of the oviraptorosaur eggs prior to their rotation into a pointed-end-posterior position and would therefore lack biological rel-evance. Alternatively, it may represent either egg rotation or for-mation of the egg blunt end posterior, both of which have been observed in some modern domestic fowl (Olsen and Byerly, 1932; Bradfield, 1951). If biologically significant, the orientation in ZMNH M8829 would require greater manipulation of the eggs in order to form a typical oviraptorosaur clutch in which the narrow end of the egg points down and away from the clutch center.

\section{Medullary Bone}

Medullary bone in modern birds serves as a calcium store during eggshell formation, and this bone tissue may persist days to weeks after oviposition (Simkiss, 1967; Chinsamy and Tumarkin-Deratzian, 2009; Werning, 2018; Canoville et al., 2019). The thickness and fully formed nature of the oviraptorosaur eggshell suggests that death occurred just prior to egg laying. The $\mathrm{ZMNH}$ M8829 adult was clearly reproductively active at the time of its death and consequently would represent a likely candidate to exhibit medullary bone, as proposed to exist in several other dino-saurs (Schweitzer et al., 2005, 2016; Lee and Werning, 2008; Hübner, 2012). However, we observed no trabeculae or other medullary bone during the visual inspection of the available cross-sections of the right femur and tibiae. Thin sections of the right femur also show an absence of such large-scale features (Fig. 4A). Where preserved, intact, poorly vascularized, lamellar endosteal tissues or fibrolamellar bone marks the interior of the femoral cortex, with the outline of the medullary cavity crosscutting these tissues. This geometry suggests normal secondary absorption along the endosteal surface, as would be expected in a growing element. Given the absence of significant taphonomic erosion of the femoral cortex and lack of trabeculae in any femoral or tibial cross-section, we interpret ZMNH M8829 as lacking medullary bone, as developed in reproductively active female birds.

Several plausible explanations may explain the absence of medullary bone in this oviraptorosaur: (1) as in most extant reptiles (Simkiss, 1967; Schweitzer et al., 2005; Dacke et al., 2015), this taxon simply may have not required medullary bone as a calcium store during eggshell deposition, instead obtaining mineral from the structural bone of the skeleton; given that this individual appears to be still growing somatically, nutrients for egg laying may have simply been acquired as the medullary cavity was expanded during normal growth; (2) alternatively, it may not have required medullary bone due to a high-calcium and -phosphorus diet, which might be expected if oviraptorosaurs were predominantly carnivorous; currently, it remains unclear whether diet can account for the absence of medullary bone observation in some extant birds (Werning, 2018); further, the lack of modern carnivorous birds of similar body mass prohibits comparison; (3) finally, this individual may have suffered from a pathological absence of this tissue or (4) all medullary bone may have been resorbed with completion of these eggs.
Regardless of the reason for its absence in this specimen, caution is required in using 'medullary bone' or its absence as a gender indicator in dinosaurs (Chinsamy and Barrett, 1997; Chinsamy and Tumarkin-Deratzian, 2009). [Note: Isles (2009) and Werner and Griebeler (2013) erroneously cite Varricchio et al. (2008) as using the absence of medullary bone as indicator of sex.] Because oviraptorosaurs are more closely related to birds than the three dinosaurs with supposed medullary bone, the absence of this tissue in a clearly reproductively active individual may challenge the avian homology of medullary tissue in these more distantly related specimens unassociated with eggs or young and supports the more cautious approach to the interpretation of medullary-like bone as advocated by both Prondvai (2017) and O'Connor et al. (2018). An adult pterosaur, also associated with two eggs, similarly lacks medullary bone (Wang et al., 2015).

\section{Sexual Dimorphism}

The preservation of caudal chevrons in a known female dinosaur sheds light on the possibility of sexual dimorphism in these elements. Past authors have occasionally sought to distinguish the sexes of archosaurs on the basis of the size of the first chevron, although Erickson et al. (2005) were subsequently unable to find support for this method in Alligator. The specimen, ZMNH M8829, represents the first known female with articulated chevrons, but it possesses a first chevron fully as long as the second, indicating that reduced chevron size is not necessary for egg laying in oviraptorosaurs. The posteriorly inclined hemal spine seen in the first chevron of ZMNH M8829 is intriguing, but with only one specimen we cannot rule out the presence of this character in all individuals.

A different example of possible sexual dimorphism in oviraptorids was recently reported in specimens of Khaan mckennai (Persons et al., 2015). The case rests on the difference in hemal spine morphology between two otherwise very similar specimens. Whereas one (MPC-D 100/1127) has simple, finger-like hemal spines for anterior chevrons, the other (MPC-D 100/1002) possesses prominent posterior projections to the second through fourth chevrons and was identified as most likely male.

Although wider distally and less rugose than in the specimen of Khaan, the anterior chevrons of ZMNH M8829 show a similar ventral posterior projection resulting in an increasingly anteroposteriorly extended hemal spine in the second through fifth chevrons. They also share a smaller, more dorsal anterior projection of the hemal spine. Presence of this morphology in ZMNH M8829 indicates that either this feature characterizes females instead or may have limited utility as a sexually dimorphic feature.

\section{Sexual versus Somatic Age}

Several features of this specimen indicate that although sexually mature, this individual was still growing somatically at the time of death. The perimeter of the femoral cortex lacks an exter-nal fundamental system and instead consists of fibrolamellar bone with laminar/subplexiform vascularization. Additionally, neurocentral sutures remain visible ('open,' sensu Brochu, 1996) on the anterior caudals and between the two preserved sacrals. This concurs with the findings of Erickson et al. (2007) that non-avian maniraptoran theropods achieved sexual maturity prior to somatic maturity and a marked slowing of growth. The femoral cortex preserves three LAGs; however, the cortex appears rather thin relative to the large medullary cavity, and bone remodeling during ontogeny likely eliminated multiple earlier-formed LAGs. 


\section{CONCLUSIONS}

ZMNH M8829 consists of the posterior portion of an oviraptorosaur with two eggs partially to fully extruded, likely by postmortem decay processes. The specimen provides an additional association of the ootaxon Macroolithus with Oviraptorosauria. The presence of two eggs further supports monoautochronic ovulation leading to the iterative laying of two eggs at daily or greater intervals. Relative egg size for this oviraptorosaur is $36-48 \%$ the value predicted for a modern bird. This highlights the gap in relative egg size but also the similarity in total egg production between non-avian maniraptorans and Neornithes. Histological tissues and open neurocentral sutures indicate that this reproductively active individual was still growing at the time of death, a pattern observed in other non-avian maniraptorans (Erickson et al., 2007).

Examination of this reproductively active maniraptoran revealed no evidence of medullary bone. Potentially this may reflect taphonomic loss, an individual anomaly, species-specific dietary or physiological aspects, or a broader absence of medullary tissue among oviraptorosaurs. The last would raise further doubts about the identity of medullary bone in dinosaurs (Schweitzer et al., 2005; Lee and Werning, 2008) more distantly related to birds. In a somatically immature individual, such as ZMNH M8829, nutrients for egg laying may have simply been acquired as the medullary cavity was expanded during normal growth.

\section{LITERATURE CITED}

Anderson, J. F., A. Hall-Martin, and D. A. Russell. 1985. Long-bone circumference and weight in mammals, birds and dinosaurs. Journal of Zoology 207:53-61.

Bailleul, A. M., J. B. Scannella, J. R. Horner, and D. C. Evans. 2016.

Fusion

patterns in the skull of modern archosaurs reveal that sutures are ambiguous maturity indicators for the Dinosauria. PLoS ONE 11: e0147687.

Bailleul, A. M., J. O'Connor, S. Zhang, Z. Li, Q. Wang, M. C. Lamanna, X Zhu, and Z. Zhou. 2019. An Early Cretaceous enantiornithine (Aves) preserving an unlaid egg and probable medullary bone. Nature Communications 10:1275.
Bakker, R. T. 1986. The Dinosaur Heresies. William Marrow, New York, $481 \mathrm{pp}$.

Balanoff, A. M., and M. A. Norell. 2012. Osteology of Khaan mckennai (Oviraptorosauria: Theropoda). Bulletin of the American Museum of Natural History 372:1-77.

Barsbold, R., P. Currie, N. P. Myhrvold, H. Osmólska, K. Tsogtbaatar, and M. Watabe. 2000. A pygostyle from a non avian theropod. Nature 403:155-156.

Barta, D. E. 2014. A phylogenetic approach to understanding dinosaur egg diversity and the evolution of reproductive traits within Dinosauria. M.Sc. thesis, Montana State University, Bozeman, Montana, $164 \mathrm{pp}$.

Blueweiss, L., H. Fox, V. Kudzma, D. Nakashima, R. Peters, and S. Sams. 1978. Relationships between body size and some life history parameters. Oecologia 37:257-272.

Böttcher, R. 1990. Neue Erkenntnisse über die Fortpflanzungsbiologie der Ichthyosaurier (Reptilia). Stuttgarter Beiträge Zur Naturkunde, Serie B 164:1-51.

Bradfield, J. R. G. 1951. Radiographic studies on the formation of the hen's egg shell. Journal of Experimental Biology 28:125-140.

Brochu, C. A. 1996. Closure of neurocentral sutures during crocodilian ontogeny: implications for maturity assessment in fossil archosaurs. Journal of Vertebrate Paleontology 16:49-62.

Brochu, C. A. 2002. Osteology of Tyrannosaurus rex: Insights from a Nearly Complete Skeleton and High-Resolution Computed Tomographic Analysis of the Skull. Society of Vertebrate Paleontology Memoir 7. Society of Vertebrate Paleontology 22(4, Supplement):1-138.

Bureau of Geology and Mineral Resources of Zhejiang Province. 1989. Regional Geology of Zhejiang Province. People's Republic of China, Ministry of Geology and Mineral Resources Geological Memoirs, Series 1, Number 11. Geological Publishing House, Beijing, China, 688 pp.

Cadena, E.-A., M. L. Parra-Ruge, J. De D. Parra-Ruge, and S. PadillaBernal. 2018. A gravid fossil turtle from the Early Cretaceous reveals a different egg development strategy to that of extant marine turtles. Palaeontology 62:533-545.

Caldwell, M. W., and M. S. Y. Lee. 2001. Live birth in Cretaceous marine lizards (mosasauroids). Proceedings of the Royal Society of London, Biological Sciences 268:2397-2401.

Campione, N. E., D. C. Evans, C. M. Brown, and M. T. Carrano. 2014. Body mass estimation in non-avian bipeds using a theoretical conversion to quadrupedal stylopodial proportions. Methods in Ecology and Evolution 5:913-923.

Canoville, A., M. H. Schweitzer, and L. E. Zanno. 2019. Systemic distribution of medullary bone in the avian skeleton: ground truthing criteria for the identification of reproductive tissues in extinct Avemetatarsalia. BMC Evolutionary Biology 19:71.

Carpenter, K. 1999. Eggs, Nests, and Baby Dinosaurs: A Look at Dinosaur Reproduction. Indiana University Press, Bloomington, Indiana, $361 \mathrm{pp}$.

Castanet, J., A. Grandin, A. Abourachid, and A. de Ricqlès. 1996. Expression of growth dynamic in the structure of periosteal bone in Anas platyrhynchos. Comptes rendus de l'Académie des sciences. Série III, Sciences de la vie 319:301-308. [French]

Chen, P.-J., Z.-M. Dong, and S.-N. Zhen. 1998. An exceptionally well-preserved theropod dinosaur from the Yixian Formation of China. Nature 391:147-152.

Cheng, Y., X. Wu, and Q. Ji. 2004. Triassic marine reptiles gave birth to live young. Nature 432:383-386.

Chinsamy, A., and P. M. Barrett. 1997. Sex and old bones? Journal of Vertebrate Paleontology 17:450.

Chinsamy, A., and A. Tumarkin-Deratzian. 2009. Pathologic bone tissue in a turkey vulture and a nonavian dinosaur: implications for interpreting endosteal bone and radial fibrolamellar bone in fossil dinosaurs. Anatomical Record 292:1478-1484.

Chinsamy, A., L. Codorniú, and L. Chiappe. 2009. Palaeobiological implications of the bone histology of Pterodaustro guinazui. Anatomical Record 292:1462-1477.

Clark, J. M., M. A. Norell, and L. Chiappe. 1999. An oviraptorid skeleton from the Late Cretaceous of Ukhaa Tolgod, Mongolia, preserved in an avian-like brooding position over an oviraptorid nest. American Museum Novitates 3265:1-36.

Currey, J. D. 2002. Bones: Structure and Mechanics. Princeton University Press, Princeton, New Jersey, 436 pp. 
Dacke, C. G., R. M. Elsey, P. L. Trosclair III, T. Sugiyama, J. G. Nevarez, and M. H. Schweitzer. 2015. Alligator osteoderms as a source of labile calcium for eggshell formation. Journal of Zoology 297:255264

Dong, Z.-M., and P. J. Currie. 1996. On the discovery of an oviraptorid skeleton on a nest of eggs at Bayan Mandahu, Inner Mongolia, People's Republic of China. Canadian Journal of Earth Sciences 33:631-636.

Erickson, G. M., A. K. Lappin, and P. Larson. 2005. Androgynous rexThe utility of chevrons for determining the sex of crocodilians and non-avian dinosaurs. Zoology 108:277-286.

Erickson, G. M., K. Curry Rogers, D. J. Varricchio, M. A. Norell, and X. Xu. 2007. Growth patterns in brooding dinosaurs reveals the timing of sexual maturity in non-avian dinosaurs and genesis of the avian condition. Biology Letters 3:558-561.

Faux, C. M., and K. Padian. 2007. The opisthotonic posture of vertebrate skeletons: postmortem contraction or death throes? Paleobiology 33:201-226.

Funston, G. F., and P. J. Currie. 2016. A new caenagnathid (Dinosauria: Oviraptorosauria) from the Horseshoe Canyon Formation of Alberta, Canada, and a reevaluation of the relationships of Caenagnathidae. Journal of Vertebrate Paleontology 36:e1160910. doi: 10.1080/02724634.2016.1160910.

Gill, F. B. 1989. Ornithology. W. H. Freeman, New York, 660 pp.

Goloboff, P. A., J. S. Farris, and K. C. Nixon. 2008. TNT, a free program for phylogenetic analysis. Cladistics 24:774-786.

Grellet-Tinner, G., L. Chiappe, M. Norell, and D. Bottjer. 2006. Dinosaur eggs and nesting behaviors: a palaeobiological investigation. Palaeogeography, Palaeoclimatology, Palaeoecology 232:294-321.

Griffiths, P. J. 1993. The question of Compsognathus eggs. Revue de Paleobiologie Volume Speciale 7:85-94.

Hone, D. W. E., A. A. Farke, and M. J. Wedel. 2016. Ontogeny and the fossil record: what, if anything, is an adult dinosaur? Biology Letters 12:20150947.

Hoyt, D. F. 1979. Practical methods of estimating volume and fresh weight of bird eggs. The Auk 96:73-77.

Hübner, T. R. 2012. Bone histology in Dysalotosaurus lettowvorbecki (Ornithischia: Iguanodontia)-variation, growth, and implications. PLoS ONE 7:e29958.

Irmis, R. B. 2007. Axial skeleton ontogeny in the Parasuchia (Archosauria: Pseudosuchia) and its implications for ontogenetic determination in archosaurs. Journal of Vertebrate Paleontology 27:350-361.

Isles, T. E. 2009. The socio-sexual behaviour of extant archosaurs: implications for understanding dinosaur behaviour. Historical Biology 21:139-214.

Ji, Q., X. Wu, and Y. Cheng. 2010. Cretaceous choristoderan reptiles gave birth to live young. Naturwissenschaften 97:423-428.

Jin, X., Y. Azuma, F. D. Jackson, and D. J. Varricchio. 2007. Giant dinosaur eggs from the Tiantai basin, Zhejiang Province, China. Canadian Journal of Earth Sciences 44:81-88.

Knell, M. J., F. D. Jackson, A. L. Titus, and L. B. Allbright III. 2011. A gravid fossil turtle from the Upper Cretaceous (Campanian) Kaiparowits Formation, southern Utah. Historical Biology 23:57-62.

Lamanna, M. C., H.-D. Sues, E. R. Schachner, and T. R. Lyson. 2014. A new large-bodied oviraptorosaurian theropod dinosaur from the latest Cretaceous of western North America. PLoS ONE 9:e92022.

Lamm, E. T. 2013. Preparation and sectioning of specimens; pp. 55-160 in K. Padian and E. T. Lamm (eds.), Bone Histology of Fossil Tetrapods: Advancing Methods, Analysis, and Interpretation. University of California Press, Berkeley, California.

Larson, P. L. 1998. The theropod reproductive system. Gaia 15:389-397.

Lee, A. H., and S. Werning. 2008. Sexual maturity in growing dinosaurs does not fit reptilian growth models. Proceedings of the National Academy of Sciences of the United States of America 105:582-587.

Li, Y., Z. Yin, and Y. Liu. 1995. The discovery of a new genus of dinosaur egg from Xixia, Henan, China. Journal of Wuhan Institute of Chemical Technology 17:38-40. [Chinese]

Liepmann, W. 1926. Leichengeburt bei Ichthyosauriern: eine paläobiologische Studie. Sitzungsberichte der Heidelberger Akademie der Wissenschaften, MathematischNaturwissenschaftliche Klasse 1926:1-11.

Liu, J., C. L. Organ, M. J. Benton, M. C. Brandley, and J. C. Aitchison. 2017. Live birth in an archosauromorph reptile. Nature Communications 8:14445.
Lü, J. 2002. A new oviraptorosaurid (Theropoda: Oviraptorosauria) from the Late Cretaceous of southern China. Journal of Vertebrate Paleontology 22:871-875.

Lü, J., and B. K. Zhang. 2005. A new oviraptorid (Theropoda: Oviraptorosauria) from the Upper Cretaceous of the Nanxiong Basin, Guangdong Province of southern China. Acta Palaeontologica Sinica 44:412-422.

Lü, J., L. Yi, H. Zhong, and X. Wei. 2013. A new oviraptorosaur (Dinosauria: Oviraptorosauria) from the Late Cretaceous of Southern China and its paleoecological implications. PLoS ONE 8: e80557.

Lü, J., R. Chen, S. L. Brusatte, Y. Zhu and C. Shen. 2016. A Late Cretaceous diversification of Asian oviraptorid dinosaurs: evidence from a new species preserved in an unusual posture. Scientific Reports 6:35780.

Lü, J., D. M. Unwin, D. C. Deeming, X. Jin, Y. Liu, and Q. Ji. 2011. An egg-adult association, gender, and reproduction in pterosaurs. Science 331:321-324.

Lü, J., G. Li, M. Kundrát, Y.-N. Lee, Z. Sun, Y. Kobayashi, C. Shen, F. Tang, and H. Liu. 2017. High diversity of Ganzhou Oviraptorid Fauna increased by a new "cassowary-like" crested species. Scientific Reports 7:6393.

Lü, J., H. Pu, Y. Kobayashi, L. Xu, H. Chang, Y. Shang, D. Liu, Y.-N. Lee, M. Kundrát, and C. Shen. 2015. A new oviraptorid dinosaur (Dinosauria: Oviraptorosauria) from the Late Cretaceous of Southern China and its paleobiogeographical implications. Scientific Reports 5:11490.

McGowan, C. 1991. Dinosaurs, Spitfires, and Sea Dragons. Harvard University Press, Cambridge, Massachusetts, $365 \mathrm{pp}$.

Mikhailov, K. E. 1991. Classification of fossil eggshells of amniote vertebrates. Acta Palaeontologica Polonica 36:193-238.

Mikhailov, K. E. 1997. Fossil and recent eggshell in amniotic vertebrates: fine structure, comparative morphology and classification. Special Papers in Palaeontology 56:1-80.

Motani, R., D.-Y. Jiang, A. Tintori, O. Rieppel, and G.-B. Chen. 2014. Terrestrial origin of viviparity in Mesozoic marine reptiles indicated by Early Triassic embryonic fossils. PLoS ONE 9:e88640.

Norell, M. A., J. M. Clark, D. Demberelyin, B. Rhinchen, L. M. Chiappe, A. R. Davidson, M. C. McKenna, P. Altangerel, and M. J. Novacek. 1994. A theropod dinosaur embryo and the affinities of the Flaming Cliffs dinosaur eggs. Science 266:779-782.

O'Connor, J. K., X. Zheng, X. Wang, Y. Wang, and Z. Zhou. 2013. Ovarian follicles shed new light on dinosaur reproduction during the transition towards birds. National Science Review 1:15-17.

O'Connor, J. K., G. E. Erickson, M. Norell, A. M. Bailleul, H. Hu, and Z. Zhou. 2018. Medullary bone in an Early Cretaceous enantiornithine bird and discussion regarding its identification in fossils. Nature Communications 9:5169.

O'Keefe, F. R., and L. M. Chiappe. 2011. Viviparity and K-selected life history in a Mesozoic marine plesiosaur (Reptilia, Sauropterygia). Science 333:870-873.

Olsen, M. W., and T. C. Byerly. 1932. Orientation of the hen's egg in the uterus and during laying. Poultry Science 11:266-271.

Osmólska, M., P. J. Currie, and R. Barsbold. 2004. Oviraptorosauria; pp. 165-183 in D. B. Weishampel, P. Dodson, and H. Osmólska (eds.), The Dinosauria, second edition. University of California Press, Berkeley, California.

Pearce, J. C. 1846. Notice on what appears to be the embryo of an Ichthyosaurus in the pelvic cavity of Ichthyosaurus (communis?). Annals and Magazine of Natural History 17:44-46.

Persons, W. S., P. J. Currie, and M. A. Norell. 2014. Oviraptorosaur tail forms and functions. Acta Palaeontologica Polonica 59:553-567.

Persons, W. S., G. F. Funston, P. J. Currie, and M. A. Norell. 2015. A possible instance of sexual dimorphism in the tails of two oviraptorosaur dinosaurs. Scientific Reports 5:9472.

Piñeiro, G., J. Ferigolo, M. Meneghel, and M. Laurin. 2012. The oldest known amniotic embryos suggest viviparity in mesosaurs. Historical Biology 24:620-630.

Prondvai, E. 2017. Medullary bone in fossils: function, evolution and significance in growth curve reconstuctions of extinct vertebrates. Journal of Evolutionary Biology 30:440-460.

Prondvai, E., and K. H. W. Stein. 2014. Medullary bone-like tissue in the mandibular symphyses of a pterosaur suggests non-reproductive significance. Scientific Reports 4:6253. 
Pu, H., D. K. Zelentisky, J. Lü, P. J. Currie, K. Carpenter, L. Xu, E. B. Koppelhus, S. Jia, L. Xiao, H. Chuang, T. Li, M. Kundrát, and C. Shen. 2017. Perinate and eggs of a giant caenagnathid dinosaur from the Late Cretaceous of central China. Nature Communications 8:14952.

Reisdorf, A. G., and M. Wuttke. 2012. Re-evaluating Moodie's opisthotonic-posture hypothesis in fossil vertebrates part I: reptiles-the taphonomy of the bipedal dinosaurs Compsognathus longipes and Juravenator starki from the Solnhofen Archipelago (Jurassic, Germany). Palaeobiodiversity and Palaeoenvironments 92:119-168.

Salamon, A., and J. P. Kent. 2014. Orientation of the egg at laying-is the pointed or the blunt end first? International Journal of Poultry Science 13:316-318.

Sato, T., Y. Cheng, X. Wu, D. K. Zelenitsky, and Y. Hsiao. 2005. A pair of shelled eggs inside a female dinosaur. Science 308:375.

Schweitzer, M. H., J. L. Wittmeyer, and J. R. Horner. 2005. Genderspecific reproductive tissue in ratites and Tyrannosaurus rex. Science 308:1456-1460

Schweitzer, M. H., W. Zheng, L. Zanno, S. Werning, and T. Sugiyama. 2016. Chemistry supports the identification of gender-specific reproductive tissue in Tyrannosaurus rex. Scientific Reports 6:23099.

Simkiss, K. 1967. Calcium in Reproductive Physiology. Reinhold, New York, $264 \mathrm{pp}$.

Simon, D. J., D. J. Varricchio, X. Jin, and S. F. Robison. 2019 Microstructural overlap of Macroelongatoolithus eggs from Asia and North America expands the occurrence of colossal oviraptorosaurs. Journal of Vertebrate Paleontology 38:e1553046. doi: 10.1080/ 02724634.2018.1553046.

Smith, H. M., G. Sinelnik, J. D. Fawcett, and R. E. Jones. 1973. A survey of the chronology of ovulation in anoline lizard genera. Transactions Kansas Academy of Science 75:107-120.

Varricchio, D. J., and F. D. Jackson. 2004. Two eggs sunny-side up: reproductive physiology in the dinosaur Troodon formosus; pp. 215-233 in P. J. Currie, E. B. Koppelhus, M. A. Shugar, and J. L. Wright (eds.), Feathered Dragons: Studies on the Transition from Dinosaurs to Birds. Indiana University Press, Bloomington, Indiana.

Varricchio, D. J., F. Jackson, J. J. Borkowski, and J. R. Horner. 1997. Nest and egg clutches of the dinosaur Troodon formosus and the evolution of avian reproductive traits. Nature 385:247-250.

Varricchio, D. J., J. R. Moore, G. M. Erickson, M. A. Norell, F. D. Jackson, and J. J. Borkowski. 2008. Avian paternal care had dinosaur origin. Science 322:1826-1828.

Wang, S., C. Sun, C. Sullivan, and X. Xu. 2013. A new oviraptorid (Dinosauria: Theropoda) from the Upper Cretaceous of southern China. Zootaxa 3640:242-257.

Wang, S., S. Zhang, C. Sullivan, and X. Xu. 2016. Elongatoolithid eggs containing oviraptorid (Theropod, Oviraptorosauria) embryos from the Upper Cretaceous of Southern China. BMC Evolutionary Biology 16:67.

Wang, X., A. W. A. Kellner, X. Cheng, S. Jiang, Q. Wang, J. M. Sayão, T. Rodrigues, F. R. Costa, N. Li, X. Meng, and Z. Zhou. 2015. Eggshell and histology provide insight on the life history of a pterosaur with two functional ovaries. Anais da Academia Brasileira de Ciéncias 87:1599-1609.

Wei, X., H. Pu, L. Xu, D. Liu, and J. Lü. 2013. A new oviraptorid dinosaur (Theropoda: Oviraptorosauria) from the Late Cretaceous of Jiangxi Province, Southern China. Acta Geologica Sinica, English Edition 87:899-904.

Weishampel, D. B., D. E. Fastovsky, M. Watabe, D. Varricchio, F. Jackson, K. Tsogtbaatar, and R. Barsbold. 2008. New oviraptorid embryos from Bugin-Tsav, Nemegt Formation (Upper Cretaceous), Mongolia, with insights into their habitat and growth. Journal of Vertebrate Paleontology 28:1110-1119.

Werner, J., and E. M. Griebeler. 2013. New insights into non-avian dinosaur reproduction and their evolutionary and ecological implications: linking fossil evidence to allometries of extant close relatives. PLoS ONE 8:e72862.

Werning, S. 2012. The ontogenetic osteohistology of Tenontosaurus tilletti. PLoS ONE 7:e33539.

Werning, S. 2018. Medullary bone is phylogenetically widespread and its skeletal distribution varies by taxon. Journal of Ornithology 159:527-543

Wilson, H. M., C. T. Heck, D. J. Varricchio, F. D. Jackson, and X. Jin. 2014. Evaluating deformation in Spheroolithus dinosaur eggs from Zhejiang, China. Historical Biology 26:173-182.

Wood-Gush, D. G. M., and A. B. Gilbert. 1969. Observations on the laying behaviour of hens in battery cages. British Poultry Science 10:29-36.

Woodward, A. S. 1906. On two specimens of Ichthyosaurus showing contained embryos. British Museum Geological Magazine 3:443-444.

$\mathrm{Xu}, \mathrm{X}$., and F. L. Han. 2010. A new oviraptorid dinosaur (Theropoda: Oviraptorosauria) from the Upper Cretaceous of China. Vertebrata PalAsiatica 48:11-18.

Xu, X., Q. Tan, J. Wang, X. Zhao, and L. Tan. 2007. A gigantic bird-like dinosaur from the Late Cretaceous of China. Nature 447:844-847.

Xu, X., U. Xing, Q.-W. Tan, S. Wang, C. Sullivan, D. W. E. Hone, F.-L. Han, Q.-Y. Ma, L. Tan, and D. Xiao. 2013. A new oviraptorid from the Upper Cretaceous of Nei Mongol, China, and its stratigraphic implications. Vertebrata PalAsiatica 51:85-101.

Zelenitsky, D. K., F. Therrien, W. G. Joyce, and D. B. Brinkman. 2008. First fossil gravid turtle provides insight into the evolution of reproductive traits in turtles. Biological Letters 4:715-718.

Zhao, Z. 1975. The microstructure of the dinosaurian eggshells of Nanxiong, Guangdong Province-on the classification of dinosaur eggs. Vertebrata PalAsiatica 13:105-117. [Chinese]

Zheng, X., J. O'Connor, F. Huchzermeyer, X. Wang, Y. Wang, M. Wang, and Z. Zhou. 2013. Preservation of ovarian follicles reveals early evolution of avian reproductive behaviour. Nature 495:507-511. 